\title{
Uma ferramenta BIM para simulação de eficiência energética nas fases iniciais de projeto
}

\section{A BIM tool for energy efficiency simulation in early stages design}

\author{
Fernando Márcio de Oliveira ${ }^{1}$ \\ Universidade Federal de Sergipe, São Cristóvão, Sergipe, Brasil, fernandomarcio@hotmail.com
}

Leonardo Salazar Bittencourt ${ }^{2}$

Universidade Federal de Alagoas, Maceió, Alagoas, Brasil, Isb54@hotmail.com

David Rodrigues Silva Dória ${ }^{3}$

Mestrando Bartlett, UCL, Aracaju, Sergipe, Brasil, arq.david.doria@outlook.com

\section{Resumo}

O grau de eficiência energética das edificações depende de decisões tomadas nas fases iniciais do projeto arquitetônico. No entanto, os programas de avaliação do seu desempenho energético demandam informações que são normalmente definidas nas etapas finais do projeto. Caso o desempenho seja insatisfatório, todo um retrabalho precisa ser empreendido. O objetivo desse trabalho é desenvolver uma ferramenta de suporte ao projetista que seja capaz de informar o nível de eficiência energética de habitações unifamiliares nas fases iniciais de projeto considerando o Regulamento Técnico da Qualidade para o Nível de Eficiência Energética de Edificações Residenciais (RTQ-R), padrão de referência brasileira. Consequentemente a ferramenta IDEEA foi desenvolvida por meio da metodologia de Design Science, baseada na ferramenta de modelagem BIM Revit da Autodesk, com as linguagens de programação Dynamo e Python. Integrando a informação armazenada no modelo paramétrico com os processos de cálculo, scripts de cálculos de desempenho do modelo coletam as informações, processam os dados, executam equações, e apresentam os resultados da eficiência energética dos ambientes, da envoltória e da unidade habitacional (resfriamento, aquecimento e refrigeração), e a pontuação total. Estes desempenhos são apresentados em tabelas e elementos gráficos, de forma amigável para a leitura, análise e definições sobre o encaminhamento do projeto. A avaliação da ferramenta foi realizada na forma de um projeto para verificar a precisão dos resultados e aferida num workshop acadêmico para verificar usabilidade. Observou-se que a interface amigável possibilitou assimilação pelos voluntários participantes do workshop, sugerindo facilidade de incorporação no processo criativo de cada projetista. Possibilitando assim, a obtenção otimizada da Etiqueta Nacional de Conservação de Energia (ENCE), concedida no âmbito do Programa Brasileiro de Etiquetagem (PBE) do INMETRO.

Palavras-chave: Eficiência energética. Processo de Projeto. RTQ-R. BIM.

\begin{abstract}
The degree of energy efficiency of buildings depends on decisions taken in the early stages of architectural design. However, energy performance assessment programs require information that is usually defined in the final stages of the project. If the performance is unsatisfactory, a whole rework needs to be undertaken. The objective of this work is to develop a tool to support the designer informing the energy efficiency level of single-family homes in the initial phases of design considering the Technical Quality Regulation for the Energy Efficiency Level of Residential Buildings (RTQ-R), reference Brazilian standard. Consequently, the IDEEA tool was developed using the Design Science methodology, based on the Autodesk Revit BIM modeling tool, with the programming languages Dynamo and Python. Integrating the information stored in the parametric model with the calculation processes. Scripts for model performance calculations collect information, process data, execute equations, and present the results of the energy efficiency of the environments, the envelope and the housing unit (ventilating, heating, and cooling), and the total score. These performances are presented in tables and graphic elements, in a friendly way for reading, analyzing and defining the project's direction. The evaluation of the tool was carried out in the form of a project to verify the accuracy of the results and academic workshop to verify usability. It was observed that the friendly interface enabled assimilation by the volunteers participating in the workshop, suggesting ease of incorporation into the creative process of each designer. Thus, enabling the optimized obtaining of the National Energy Conservation Label, granted under the Brazilian Labeling Program of INMETRO.
\end{abstract}

Keywords: Energy efficiency. Design process. RTQ-R. BIM.

How to cite this article:

OLIVEIRA, F. M.; BITTENCOURT, L. S.; DORIA, D. R. S. Uma ferramenta BIM para simulação de eficiência energética nas fases iniciais de projeto. PARC Pesquisa em Arquitetura e Construção, v. 11, p. e020003, 15 mar. 2020.

DOI:https://doi.org/10.20396/parc.v11i0.8653782 


\section{Introdução}

De modo geral, os edifícios consomem $20 \%$ a $40 \%$ do total de energia elétrica produzida; percentual acima dos valores da indústria e dos transportes (PÉREZ-LOMBARD; ORTIZ; POUT, 2008; HOJJATI; WADE, 2012).

No Brasil, as edificações são identificadas como a principal demanda de eletricidade do país, sendo responsáveis por cerca de 50\% do total deste consumo (MME, 2018). Avaliase que o setor residencial tem uma previsão de crescimento em torno de $23 \%$ até 2030 , refletindo as hipóteses de crescimento do nível de renda e de sua maior distribuição, como aconteceu nos anos de 2005 a 2014. Estima-se que o consumo de eletricidade residencial per capita, cujo valor atual é de apenas $38 \mathrm{kWh} / \mathrm{mês} / \mathrm{hab}$., possa chegar, em 2030, a $99 \mathrm{kWh} / \mathrm{mês} / \mathrm{hab}$., que ainda é um valor inferior aos parâmetros internacionais, porém teríamos um impacto significativo no consumo (LAUSTSEN, 2008).

Por esse motivo, o desempenho energético residencial tem assumido uma importância crescente em todo o mundo. A Agência Internacional da Energia descreve a eficiência energética como o primeiro combustível com maior importância que qualquer tecnologia de geração (INTERNATIONAL ENERGY AGENCY, 2014). Estudos comprovam que o maior potencial de economia na obtenção de eficiência energética está no setor da construção civil (CULLEN; ALLWOOD; BORGSTEIN, 2011; BORGSTEIN; LAMBERTS; HENSEN, 2016).

Eficiência energética na arquitetura deveria ser um atributo inerente a todos os edifícios, pois representa um forte potencial para proporcionar conforto (térmico, visual e acústico) aos usuários, com baixo consumo de energia (FREIRE; AMORIM, 2011; LAMBERTS, 2016).

Uma alternativa para reduzir o consumo de energia nos edifícios é estabelecer padrões para a avaliação e classificação de edifícios em termos de eficiência energética que sejam reconhecidos e utilizados nacionalmente. Os dois principais mecanismos para avaliar o desempenho energético no setor de construção civil são: (i) regulamentos, em que se definem os padrões mínimos adotados e; (ii) certificados ou etiquetas de consumo de energia, mecanismos que uniformizam os procedimentos usados para determinação dos níveis de eficiência, destinados a estimular um desempenho superior ao padrão normativo (CASALS, 2006). Além disso, um edifício com uma boa classificação energética obtida por meio de certificados ou etiquetas pode ter um reconhecimento oficial, assim como atingir maiores valores de mercado (FOSSATI et al., 2016).

Etiquetagem de eficiência energética no Brasil

A partir de 2009, uma parceria entre o Instituto Nacional de Metrologia, Qualidade e Tecnologia (INMETRO) e a Eletrobrás viabilizou a implantação dos Regulamentos para o Nível de Eficiência Energética de Edificações (INMETRO, 2012), que servem de base para a criação de um sistema de certificação que utiliza etiquetas para o cálculo do desempenho das edificações em relação à eficiência energética (UMAKOSHI, 2014). Atualmente, a aplicação destes regulamentos ainda é de caráter voluntário, com exceção de edificações públicas federais.

O nível de eficiência energética, avaliado mediante a aplicação da metodologia descrita nos regulamentos citados, consiste em uma etiqueta, semelhante às emitidas pelo INMETRO para equipamentos e eletrodomésticos (Figura 1 à esquerda). A classificação é apresentada na forma de níveis de consumo, cuja categorização varia de $\mathrm{A}$ (mais eficiente) a $E$ (menos eficiente). No caso das edificações, existem dois tipos de etiquetas: uma para o projeto e outra para a edificação construída (INMETRO, 2012). 
A avaliação do nível de eficiência energética é feita mediante a aplicação de métodos descritos nos Regulamentos Técnicos da Qualidade (RTQ), sendo que para edificações comerciais, de serviço e públicas usa-se o RTQ-C e para edificações residenciais utilizase o RTQ-R. Neste último são avaliados o envelope (ou envoltória) da construção (Figura 1, à direita) e o sistema de aquecimento de água (INMETRO, 2012).

Figura 1 - Etiqueta de Edificações PBE Edifica (à esquerda), Esquema tridimensional destacando o envelope da edificação do corpo central (à direita)
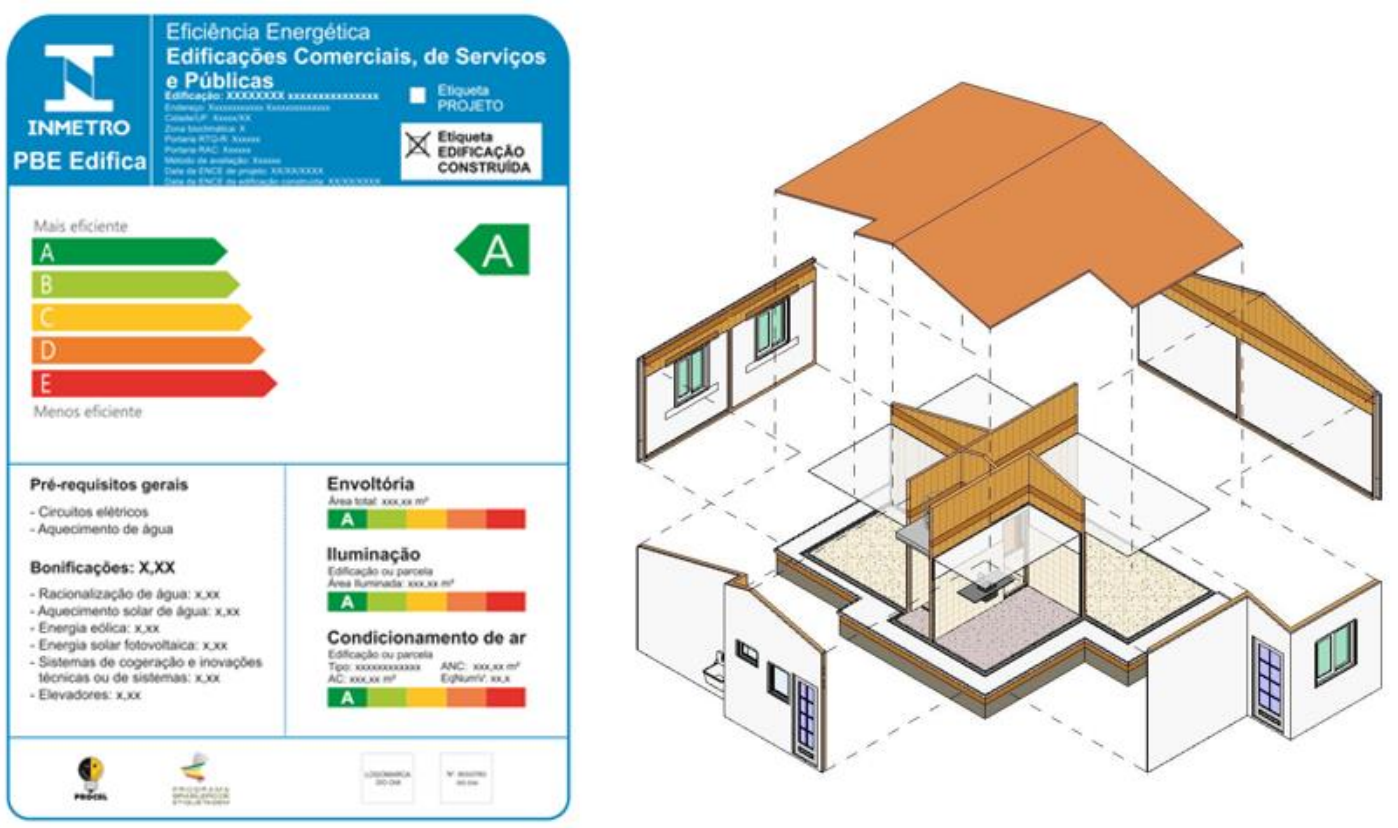

Fonte: PROCEL (2012), adaptado pelos autores

Em residências com condicionamento artificial, a avaliação do envelope considera dois aspectos (FOSSATI et al., 2016). O primeiro diz respeito ao consumo para refrigeração (CR), com base no número de graus-hora de resfriamento (GHR) para a obtenção de conforto térmico no verão. O segundo aspecto refere-se ao consumo de energia para aquecimento (CA), que depende do número de graus-hora de aquecimento (GHA), para a obtenção de conforto no inverno.

As características geométricas dos modelos são consideradas como variáveis previstas, que são utilizadas para estimar três variáveis dependentes. Para selecionar as variáveis a serem utilizadas no desenvolvimento das equações de regressão, os parâmetros de construção foram divididos em quatro categorias FOSSATI et al., 2016):

1) variáveis térmicas como transmitância térmica, absorção solar e capacidade térmica dos elementos de construção;

2) variáveis geométricas, como volume e áreas dos ambientes, altura do teto, áreas das paredes, áreas envidraçadas e áreas abertas para ventilação;

3) variáveis binárias como contato com o solo, exposição do telhado, palafitas, sombreamento nas áreas envidraçadas, tipo de construção (pesado ou leve);

4) variáveis combinadas, combinação de variáveis térmicas e geométricas como variáveis físicas termo geométricas.

Processo de projeto e simulações

Geralmente, as preparações para simulação energética começam apenas quando as decisões arquitetônicas e o desenho do sistema HVAC já avançaram o suficiente para a 
representar, adequadamente, o comportamento térmico das edificações (BAZJANAC, 2008). Na prática, isso significa que o início da análise térmica só tem lugar depois de algumas decisões fundamentais já tiverem sido tomadas, algumas potencialmente críticas para a eficiência energética do edifício.

O processo de projeto é marcado pela contínua ocorrência de dilemas arquitetônicos, bem como do posicionamento do arquiteto frente a eles. Esses dilemas, se materializam como conflitos entre as demandas oriundas dos diferentes condicionantes arquitetônicos: caráter da obra; configuração do partido arquitetônico; demandas bioclimáticas; forma, orientação e topografia do terreno; vistas e vegetação a serem preservadas; definição do sistema construtivo; localização, dimensionamento e tipologia das aberturas; colorido do edifício; entre outras demandas (BITTENCOURT; MONTEIRO; YANNAS, 2015).

$\mathrm{Na}$ elaboração do projeto, o arquiteto depara-se com um conjunto de possibilidades para definição do partido arquitetônico, desde os esboços iniciais até o projeto executivo. As definições e ajustes inerentes a cada etapa do projeto afetam sua eficiência energética e, por sua vez, sugerem adaptações que precisam ser implementadas, como o uso de protetores solares em determinadas fachadas, por exemplo (MOHAMED, 2012; FERREIRA, 2015). Cada vez mais, as escolhas são baseadas em critérios estabelecidos, considerando os principais aspectos que embasarão a decisão final, isto é, o contexto mais amplo do projeto (BITTENCOURT; MONTEIRO; YANNAS, 2015). No caso da eficiência energética, a etapa inicial do projeto do edifício é uma das mais importantes. Verifica-se aí a importância de monitorar, em tempo real, o impacto exercido por modificações inerentes à evolução do projeto (LOBOS; TREBILCOCK, 2014).

O aumento da complexidade dos projetos associado a crescente exigência de desempenho e ao aumento do número de profissionais especializados participando de um mesmo projeto têm acarretado maior necessidade de obtenção, filtragem e organização de informações de projeto (MITCHELL; MCCULLOUGH, 1995 apud ANDRADE, 2012). O resultado é que o número de informações torna-se excessivamente grande e difícil de ser gerenciado de modo analógico (ANDRADE, 2012). A fim de superar este obstáculo, uma nova abordagem que utiliza um processo de projeto integrado deve ser introduzida na indústria de construção (ALAWINI et al., 2013).

O Processo de Projeto Integrado (IDP - Integrated Design Process) sugere uma abordagem colaborativa na operação nas fases iniciais do projeto e define a equipe de projeto composta de atores, onde os atores referem-se a todos os participantes que têm uma relevante influência no conteúdo e curso da concepção e realização do projeto. Isso determina a necessidade de um modelo integrado por várias contribuições, incluindo arquitetos e engenheiros (NEGENDAHL, 2015).

Os custos de implantação dessas modificações também poderão ser maiores, reforçando que as fases iniciais do processo são as mais adequadas e menos dispendiosas para ajustar os projetos na busca por uma melhor eficiência energética (DAVIS, 2017).

Na Figura 2 verifica-se que se torna cada vez mais difícil de alterar um projeto arquitetônico à medida que o desenvolvimento avança para as fases finais do processo. Os custos dessas decisões para execução também poderão ser maiores. Impactos positivos dos ajustes na qualidade do projeto tendem a diminuir à medida que o processo evolui, reforçando as fases iniciais do processo como as mais adequadas e menos dispendiosas para se definir o melhor desempenho do edifício. 


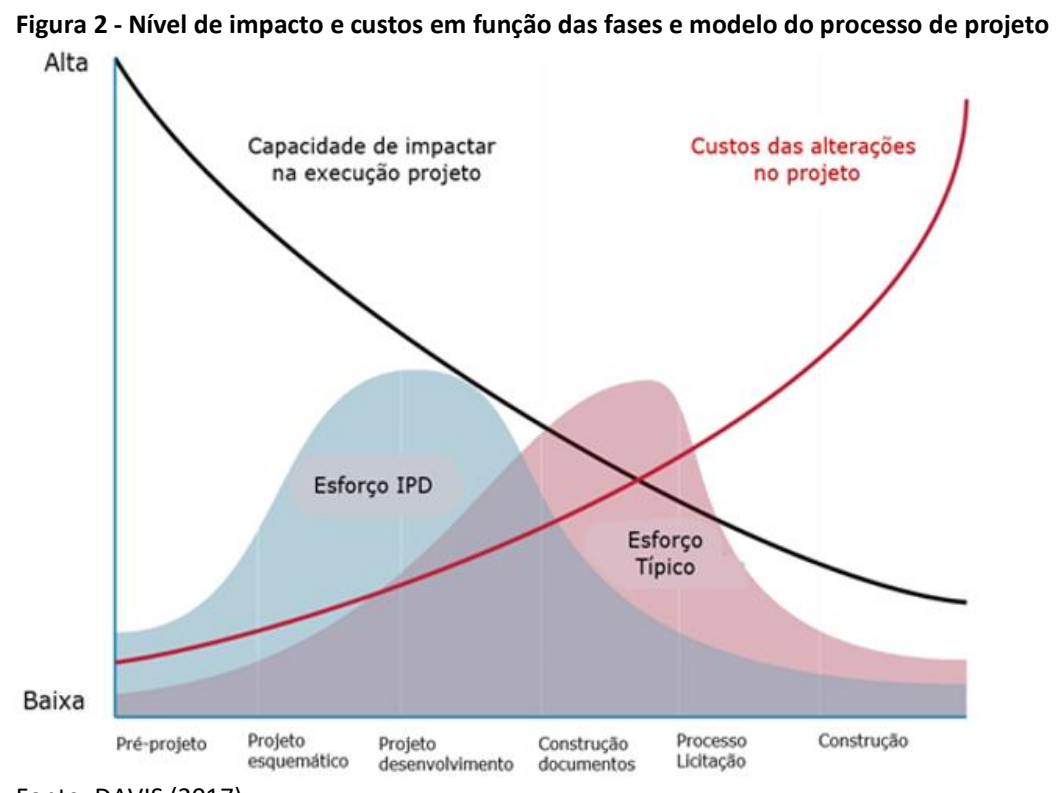

Fonte: DAVIS (2017)

Em vista disso, as fases iniciais do projeto são as mais adequadas (e menos dispendiosas) para se definir o desempenho do edifício. Tal afirmação reforça a necessidade de se avaliar, comparativamente, o impacto exercido por diferentes configurações arquitetônicas no nível de eficiência energética da edificação.

BIM e Linguagem de Programação

Por conta de transformações e exigências atuais no processo de projeto, o Building Information Modeling (BIM) passou a ser mais usado, não apenas como meio de armazenar e gerenciar informações sobre o edifício, mas também para contribuir para a transformação e a geração de novas soluções de projeto (EASTMAN et al., 2011).

O BIM baseia-se num conjunto inter-relacionado de processos, tecnologias e políticas de gerenciamento do fluxo da informação digital na Arquitetura, Engenharia, Construção e Operação (AECO) (SUCCAR, 2009). Como processos, o BIM envolve o projeto, a construção, a fabricação, o uso e a manutenção do edifício. Como tecnologia, relaciona-se com o desenvolvimento e suporte de sistemas e aplicativos de comunicação, servidores de modelo e tecnologias de banco de dados. Como política, engloba as melhores práticas, focadas em diretrizes, regulamentações, padronizações e pesquisas (ANDRADE, 2012).

O BIM evolui para se estabelecer como prática padrão da indústria de construção, desde a fase inicial do processo de projeto à gestão do edifício durante o seu uso. O BIM apresenta vantagens ao permitir fluxos de trabalho e decisões de projeto baseadas em dados (SANTIAGO, 2016). Uma importante decisão para disseminação do BIM no país foi a publicação do Decreto n. 9.377 do governo brasileiro que tem a finalidade de promover um ambiente adequado para o desenvolvimento de estudos e trabalhos em BIM, bem como para sua difusão no país (BRASIL, 2018). O decreto foi revogado no ano seguinte, mas manteve i incentivo a disseminação do BIM (BRASIL, 2019).

As ferramentas computacionais que compõem a tecnologia BIM contemplam aplicativos de autoria e integração (TOBIN, 2008). Ferramentas de autoria podem ser definidas em dois tipos: as de modelagem e as de análise ou simulação sobre o modelo. Os programas mais conhecidos de ferramentas de autoria para modelagem paramétrica BIM são: Archicad, Revit (Architecture, Structure e MEP) e Vector Work. Já ferramentas 
como Ecotect e Robot são exemplos de ferramentas de autoria para análise e simulação do desempenho ambiental e estrutural, respectivamente (RUSCHEL et al., 2013).

As ferramentas baseadas na tecnologia BIM têm grande potencial de auxílio ao projeto e podem ser incorporadas desde a fase de análise até a fase de síntese e, portanto, podem ser uma parte ativa do processo de projeto desde o início (THUESEN; KIRKEGAARD; JENSEN, 2010).

Ferramentas baseadas em linguagem de programação visual (VPL) permitem a codificação de regras que, ao serem processadas, podem gerar modelos 3D, ou mesmo interferir nos modelos existentes (STAVRIC; MARINA, 2011) como também no suporte à fabricação digital (LACHAUER; RIPPMANN; BLOCK, 2010). As ferramentas Dynamo®, Grasshopper ${ }^{\circledR}$ e Generative Components ${ }^{\circledR}$ são exemplos de aplicativos que utilizam esse tipo de linguagem (MONTEIRO, 2016). A ideia principal por trás desse tipo de linguagem é facilitar a sua utilização e aprendizado por meio do uso de artefatos gráficos, em oposição ao uso de uma linguagem de programação textual (DEHOUCK, 2015).

O Dynamo é uma VPL de código aberto que interage com o Revit para ampliar seus recursos paramétricos para o nível de projeto do BIM (MONTEIRO, 2016). O Dynamo integra as versões mais recentes do programa de modelagem virtual Autodesk Revit e, a partir da versão 2017.2 surgiu também o aplicativo Dynamo Player, que permite a execução dos programas desenvolvidos com maior agilidade, sem a necessidade de abrir os códigos de programação.

Uma integração sistemática paramétrica em BIM e a análise da eficiência energética podem fornecer um novo fluxo de trabalho que tornaria estas análises mais acessíveis no que se refere ao processo de projeto. O BIM pode fornecer informações construtivas relevantes para as análises de eficiência energética. Se usado apropriadamente, pode economizar uma quantidade significativa de tempo e esforço na preparação de dados de entrada para a simulação de desempenho de construção, reduzindo prazos e margens de erros (KUMAR, 2008).

\section{Objetivo}

Este trabalho tem como objetivo apresentar uma ferramenta que informe ao projetista de habitações unifamiliares os níveis de eficiência energética desde os estágios iniciais do projeto arquitetônico e no decorrer de sua elaboração no programa de modelagem virtual.

\section{Método}

A metodologia adotada baseia-se na Design Science Research Methodology (DSRM), proposta por Peffers (2006). A DSRM é definida como a ciência que procura desenvolver e projetar soluções para melhorar sistemas existentes, resolver problemas ou, ainda, criar novos artefatos que contribuam para uma melhor atuação humana, seja na sociedade, seja nas organizações (DRESCH; LACERDA; ANTUNES, 2015). É um método que fundamenta e operacionaliza a condução de pesquisas quando o objetivo a ser alcançado é um artefato que permita soluções satisfatórias aos mais diversos problemas práticos.

Para alcançar o objetivo proposto, adotou-se um processo metodológico iterativo com seis etapas (PEFFERS et al., 2006), considerando os passos característicos do processo de pesquisa construtiva (DSRM), descritos a seguir.

1. Identificação do problema: definição dos pontos que motivaram a realização da pesquisa - a inexistência de ferramenta computacional capaz de informar aos 
arquitetos qual a eficiência energética do edifício nas fases iniciais do processo de elaboração do projeto arquitetônico.

2. Definição dos resultados esperados: integração da avaliação da eficiência energética ao projeto arquitetônico, apresentando os algoritmos e procedimentos utilizados nos modelos virtuais, e espera-se que a ferramenta computacional concebida seja capaz de responder ao problema identificado na etapa anterior. Para verificação dos níveis de eficiência energética de uma habitação unifamiliar adotaram-se os critérios e padrões referenciais e os algoritmos e procedimentos propostos pelo RTQ-R do INMETRO (2012).

3. Projeto e desenvolvimento: definição das etapas do projeto em que serão realizadas avaliações de eficiência energética, bem como dos critérios e padrões referenciais adotados. A ferramenta foi desenhada com base nos objetivos definidos para responder ao problema:

- Capacidade de fornecer respostas para as soluções de projeto com eficiência energética durante o processo de projeto no BIM que auxilie na tomada de decisão;

- Capacidade de ser integrada a um amplo espectro de cenários de projeto;

- Fácil implantação e análise por projetistas no processo de projeto.

Um protótipo foi desenvolvido para testar usabilidade geral e precisão dos resultados obtidos, podendo ser usado para testes e validação nas próximas etapas.

4. Demonstração: nessa etapa, demonstrou-se o protótipo da ferramenta para resolver pequenas amostras de problemas, através de ensaios em um projeto que serviram para avaliar a utilidade e dificuldades da solução desenvolvida. Realizaramse também estudos de caso com diferentes tipologias para análise do comportamento da ferramenta.

5. Avaliação: nessa etapa, realizou-se um experimento na forma de workshop de treinamento e acompanhamento de grupos específicos de profissionais e alunos de arquitetura e urbanismo, bem como identificação das eventuais limitações e potencialidades desta, com enfoque em habitações unifamiliares.

As etapas acima foram realizadas num processo iterativo de desenvolvimento envolvendo sequencias, simultaneidade e iterações.

$\mathrm{Na}$ etapa de projeto da ferramenta, os objetivos foram definidos com base no conhecimento reunido na revisão da literatura, de forma a abordar o problema identificado considerando os métodos disponíveis, sendo eles:

- Informar o projetista a respeito da eficiência energética durante o processo de projeto no BIM;

- Evitar que o projetista adote, nas etapas iniciais do projeto, um partido inadequado do ponto de vista da eficiência energética;

- Ter capacidade de ser integrada a um amplo espectro de variadas metodologias de processo de projeto usadas pelos projetistas;

- Apresentar agilidade de resposta, compreensível para os profissionais que atuem com projeto de arquitetura, com uma interface amigável.

A possibilidade de integração entre os programas Dynamo e Autodesk Revit 2019 motivou a sua escolha para essa pesquisa. Além disso permitiu o desenvolvimento de uma ferramenta que funcionasse diretamente em um programa de modelagem, interagindo facilmente no processo projetual. O mesmo pode ser obtido com outros 
programas, como o ArchiCAD e Grasshopper, e Vectorworks e Marionete, com mudanças de implementação demandadas.

\section{Ensaios da ferramenta}

Como demonstração da ferramenta realizaram-se ensaios tendo como modelo uma habitação unifamiliar e dois estudos de caso com diferentes tipologias. Neste processo de conferência dos resultados alcançados observava-se a validade dos resultados.

Um workshop foi realizado na Universidade Federal de Sergipe (UFS), Campus Laranjeiras, não havendo restrições além da necessidade de saber usar o Revit 2019. Não foi exigido dos participantes conhecimento em eficiência energética e do RTQ-R. O workshop foi divulgado para o curso de graduação de Arquitetura e Urbanismo, bem como também foram convidados arquitetos que atuam em escritórios de arquitetura que usam a ferramenta Revit.

O workshop um nivelamento abordando questões relativas à Etiquetagem, treinamento na ferramenta e a boas práticas na modelagem da informação. Os participantes foram orientados a aplicar o conhecimento e ferramenta apresentados para criar um projeto de habitação unifamiliar, desenvolver a modelagem com as informações necessárias, gerar e analisar os resultados e fazer ajustes para a melhoria da eficiência energética.

$\mathrm{Na}$ última etapa do workshop os participantes responderam a um questionário sobre uso e a aplicação da ferramenta, sendo solicitada uma avaliação de 0 a 10 e um comentário sobre a nota dada, descritos sucintamente a seguir:

1. Como você descreveria suas impressões na utilização da ferramenta IDEEA no desenvolvimento de projeto e simulação da eficiência energética do edifício?

2. Como você avalia as atividades desenvolvidas com a ferramenta IDEEA, integrando o processo de projeto e eficiência energética no edifício?

3. Conseguiu relacionar o desenvolvimento do projeto a eficiência energética do edifício?

4. Sentiu dificuldades para configurar as informações necessárias ao processamento e equações durante o processo de projeto? Caso tenha tido alguma dificuldade, como você poderia descrever?

5. Gostaria de sugerir alterações e melhorias na ferramenta IDEEA? Quais?

\section{Resultados}

A estrutura da ferramenta IDEEA está baseada na integração, por um lado, de processos e tecnologia BIM, modelagem paramétrica e programação visual e, por outro, e na interação entre projetistas. Na Figura 3 podem ser observadas as etapas de implantação da ferramenta, que seguem um fluxo de trabalho com o objetivo de fornecer suporte para uma melhor tomada de decisão, visando a obtenção de níveis razoáveis de eficiência energética do edifício. 
OLIVEIRA, Fernando; BITTENCOURT, Leonardo; DÓRIA, David

Uma Ferramenta BIM de Simulação de Eficiência Energética nas Fases Iniciais de Projeto

Figura 3 - Processo de implantação das etapas e ações no fluxo de trabalho IDEEA

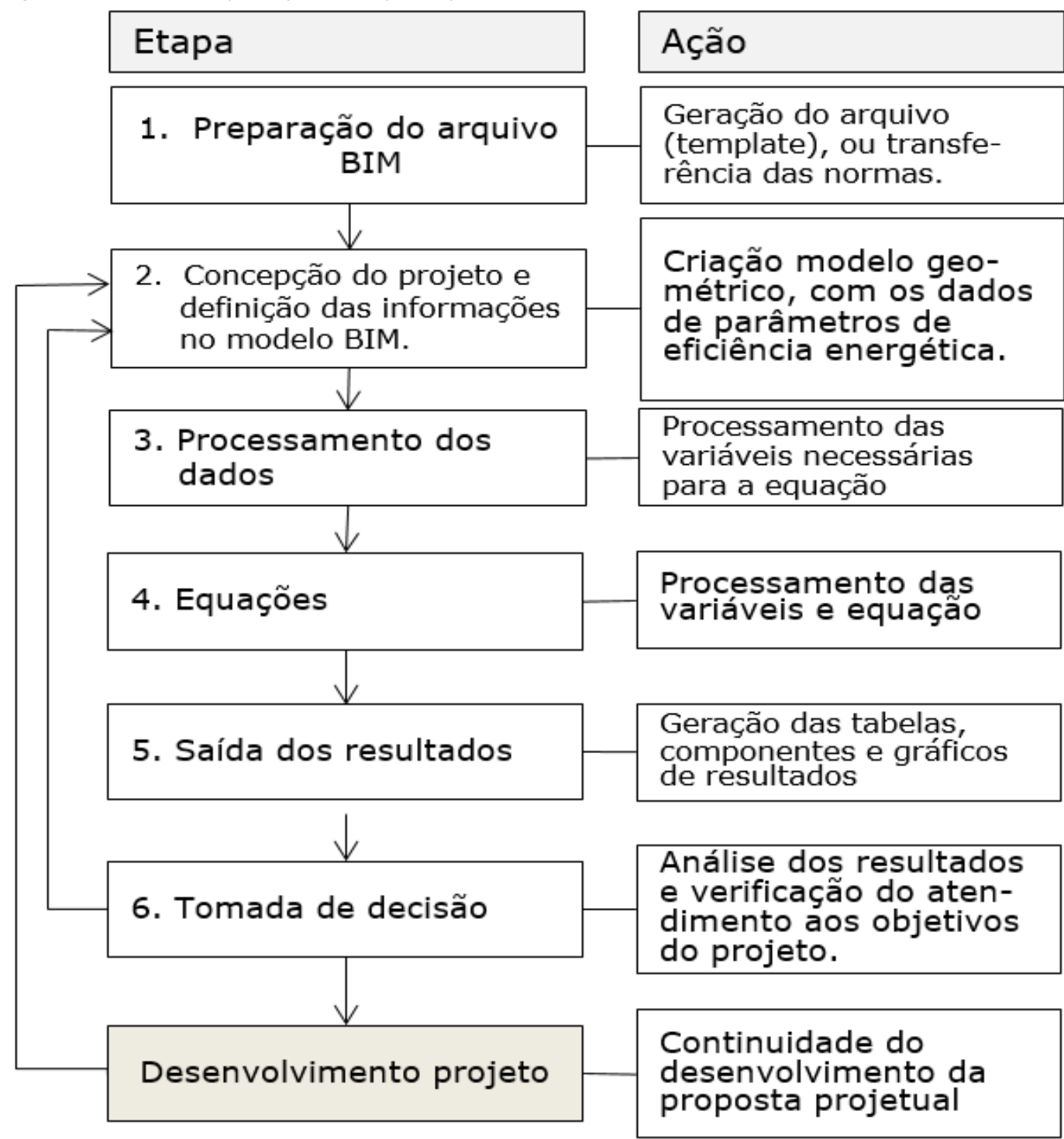

Fonte: Autores

A sequência das etapas não precisa ser exatamente como exposta na Figura 3, uma vez que o próprio processo criativo não é linear. De forma geral, a ferramenta consiste em preparação do modelo virtual (arquivo BIM); concepção do partido arquitetônico da habitação; processamento dos dados e cálculo das equações; saída dos resultados, exibidos graficamente e em dados, de forma a facilitar o entendimento; e tomada de decisão de projeto pelos projetistas. Cada uma destas etapas têm uma ação correspondente e produtos como apresentado na Figura 3.

Caso a análise dos resultados indique um atendimento não suficiente aos objetivos propostos de projeto, retorna-se à etapa de concepção, fazendo os ajustes para melhoria e atendimento aos objetivos. Caso os resultados estejam de acordo com o planejado, segue-se o desenvolvimento do projeto, podendo, a qualquer momento, retomar-se o início do processo, em caso de ajustes necessários.

Essa estrutura foi desenvolvida dentro de um programa de modelagem BIM amplamente utilizado, Autodesk Revit 2019, juntamente com o Dynamo 1.3 e o Python, para integrar a informação armazenada no modelo virtual paramétrico e simular a 
eficiência energética do edifício, fornecendo respostas de desempenho mais acessíveis no processo de projeto.

O fluxograma geral da ferramenta IDEEA está apresentado na Figura 4 e possui três fases: (i) Preparação / Entradas, (ii) Processamento, e (iii) Equações / Saídas, para uma melhor compreensão e uso pelos projetistas. Essas fases são descritas a seguir.

Figura 4 - Fluxograma geral da ferramenta IDEEA

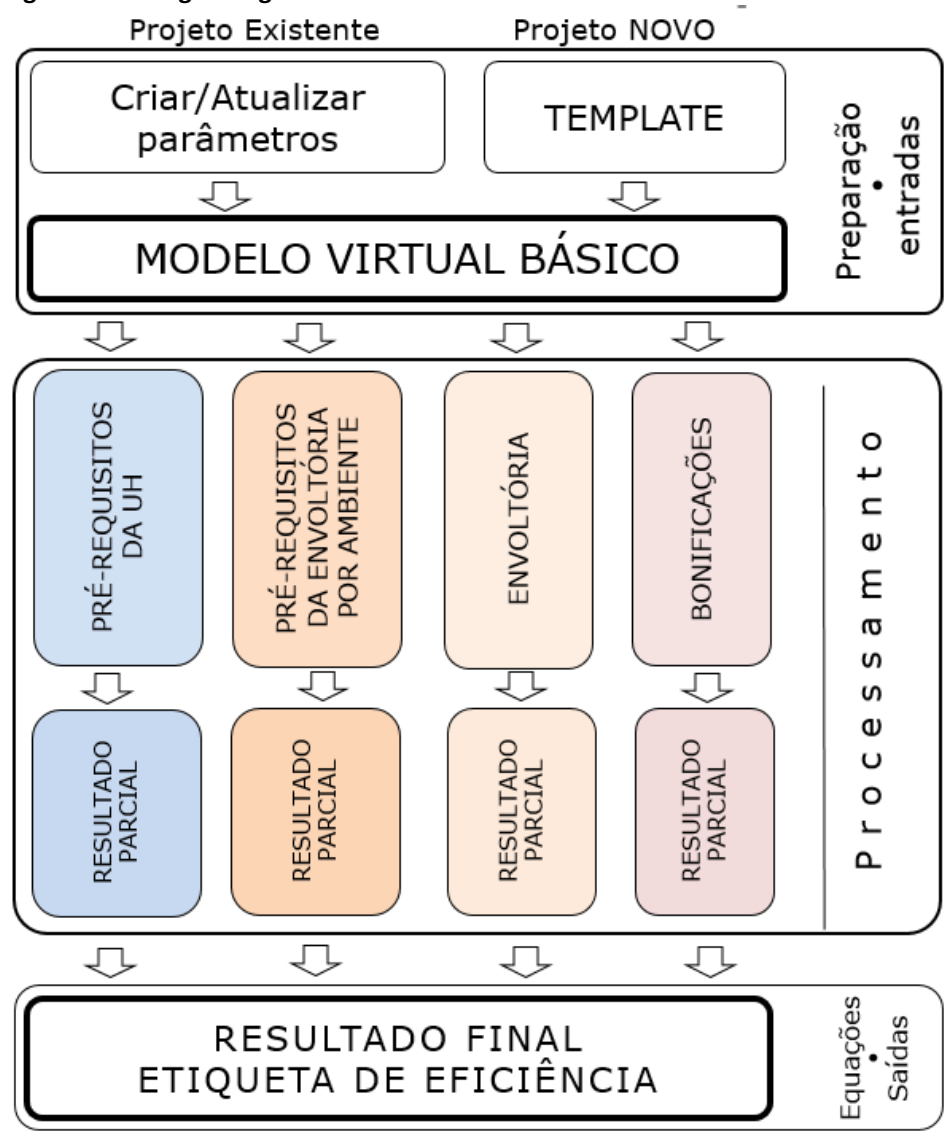

Fonte: Autores

$1^{a}$ Fase - Preparação do modelo virtual e entrada de dados

Nessa fase são inseridas as informações necessárias para o processamento dos dados. O modelo virtual deve conter as variáveis de entrada do processo conforme listado a seguir:

1. informações referentes ao projeto: zona bioclimática, região geográfica, Equivalente numérico de Aquecimento de Água (EqNumAA), medidor individual de água, medidor individual de energia e cota média do meio-fio;

2. características térmicas dos componentes (absortância, transmitância e refletância): paredes, coberturas, forros, portas e janelas;

3. caracterização dos ambientes: tipo (Banheiro, Circulação, Cozinha, Dormitório, área Externa, Garagem, outros ambientes de permanência Prolongada, Varanda e Serviço), incluindo outras variáveis que afetem a eficiência energética do edifício como contato com o pilotis, solo, cobertura, iluminação artificial eficientes, condicionador de ar selo A ou PROCEL, dispositivo especial de ventilação, refrigerador eficiente e ventilador de teto; 
4. geometria da edificação: a forma arquitetônica e seus respectivos componentes arquitetônicos como paredes, cobertura, pisos e esquadrias.

Para preparação do modelo virtual dois caminhos foram propostos, um considerando o início de um novo projeto e outro para um projeto já existente. Rotinas de auxílio foram desenvolvidas para cada um. A rotina de PROJETO NOVO inicia-se por meio do template 'IDEEA_Template' para arquivos Revit, onde estão inseridos os parâmetros necessários descritos anteriormente para a entrada de dados e concepção da geometria do projeto. No 'IDEEA_Template' estão disponibilizados os componentes mais comuns dos elementos arquitetônicos, de acordo com o Anexo Geral $V$ da Portaria INMETRO $\mathrm{N}^{\circ} 50 / 2013$ (INMETRO, 2013), com valores de Absortância Solar (AS) definidos para a pintura externa das paredes na cor branca, de acordo com a Tabela B.2 do Anexo B da NBR 15220-2 (ABNT, 2005).

Na rotina de PROJETO EXISTENTE, o projetista já tem uma modelagem a partir de um projeto existente, mas não elaborada em um template IDEEA. Para essa atualização foi desenvolvido um script ${ }^{2}$ 'IDEEA_Inserir_Template' que insere os parâmetros necessários no arquivo de modelagem para a entrada e saída de dados, tabelas configuradas e componentes de anotação.

O modelo virtual BIM é composto por componentes onde estão as informações necessárias para as simulações de eficiência energética como mostra a Figura 5. Desta forma, para os cálculos é necessária a modelagem da edificação com os componentes: portas e janelas, paredes, coberturas, pisos, forros, sistema de aquecimento de água, equipamentos de racionamento de água e alguns eletrodomésticos. É do modelo que a ferramenta vai extrair os dados para o processamento dos cálculos das variáveis do RTQ-R.

Figura 5 - Componentes do Modelo Virtual para simulações de eficiência energética do RTQ-R

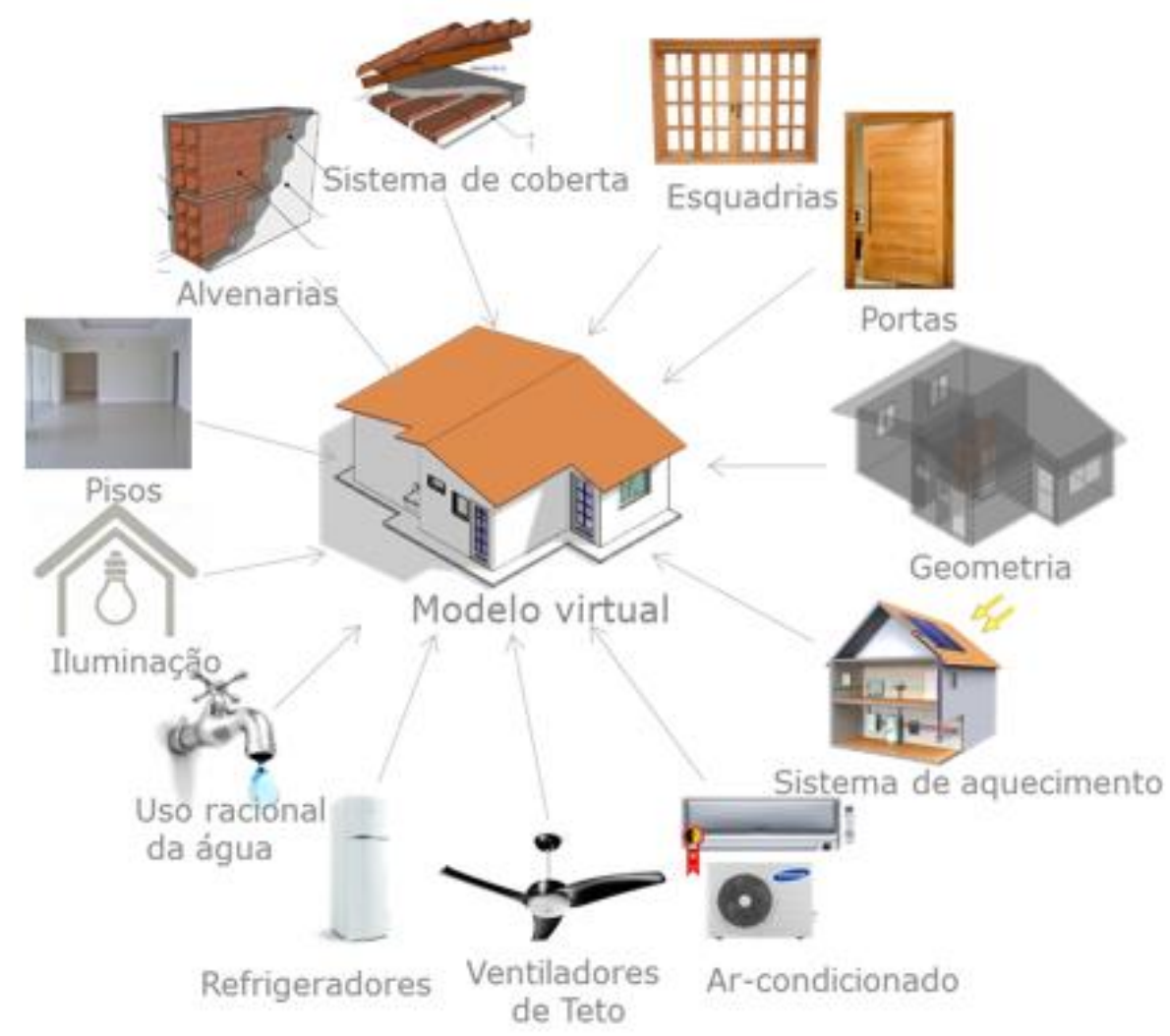

Fonte: Autores 


\section{$2^{a}$ Fase - Processamento dos dados}

Nessa fase, são extraídas do modelo as informações necessárias ao processamento. Serão também observados pré-requisitos referentes à Unidade Habitacional (UH) ou ao envelope e calculadas as variáveis dos ambientes de permanência prolongada que podem afetar a Eficiência energética da edificação (EEE). Para tal, foi desenvolvido o script 'IDEEA_Processamento', responsável por capturar os dados relativos ao modelo que será examinado, sendo essas informações filtradas, processadas e organizadas no arquivo da modelagem. Os valores das variáveis abaixo listadas são calculados:

a) verificação ao atendimento dos pré-requisitos da UH - medição individual de água e energia, ventilação cruzada e banheiros com ventilação;

b) verificação ao atendimento dos pré-requisitos da envoltória - paredes, cobertura, iluminação e ventilação natural;

c) verificação das características térmicas das paredes e coberturas, referentes a absortância solar ( $(\alpha)$, transmitância térmica $(U)$ e capacidade térmica $(C T)$, área das paredes e aberturas por orientação, porosidade e abertura das fachadas, área das paredes internas, pé-direito, fator de ventilação (Fvent) e sombreamento das esquadrias, profundidade de iluminação, refletância do teto, Graus Horário de Resfriamento (GHR), Consumo de Energia para Aquecimento (CA) e Consumo de Energia para Refrigeração $(C R)$.

\section{$3^{a}$ Fase - Equações e saídas}

No script 'IDEEA_Equação' são realizados os cálculos das variáveis que determinam a eficiência dos ambientes de permanência prolongada, da envoltória e da Unidade Habitacional. Nesse momento são utilizadas as informações geradas na fase anterior e alimentadas as equações de acordo com a sua zona bioclimática (ZB), junto com uma relação de constantes que compõem a equação.

A Equação descrita abaixo é utilizada no processo para cálculo dos GHR das ZB's 5 e 8 e as constantes presentes (Tabela 1). As outras equações estão disponíveis no Manual do RQT-R (ELETROBRAS; PROCEL; CB3E, 2012).

GHR $=(a)+(b *$ somb $)+(c * \alpha c o b)+(d * \alpha p a r)+(e *$ CTbaixa $)+(f *$ PambO $)+(g *$ solo * $A U a m b)+(h * A P a m b L * U p a r * \alpha p a r)+(i * P a m b N)+(j *$ pil $* A U a m b)+(k * A A b o *(1-$ $s o m b))+(l * F v e n t)+(m * A A b s *(1-s o m b))+(n * U c o b * \alpha c o b * c o b * A U a m b)+(o * c o b *$ $A U a m b)+(p * A b N)+(q * A P a m b N)+(r * A P a m b S)+(s *$ PambL $)+(t * A P a m b N * U p a r *$ $\alpha p a r)+(u * A b L)+(v * P D / A U a m b)+(w *$ solo $)+(x *$ SomApar $)+(y * A P a m b N *$ Upar $* \alpha p a r)+$ $(u * A b L)+(v * P D / A U a m b)+(w *$ solo $)+(x$ SomApar $)+(y * A P a m b O) U p a r * \alpha p a r)+(z *$ $C T c o b)+(a a * C T a l t a)+(a b * U c o b)+(a c * A P a m b L * \alpha p a r)+(a d * P a m b S)+(a e * p i l)+(a f *$ $A A b L *(1-s o m b))+(a g * A A b N * s o m b)+(a h * P D * A U a m b)+(a i * A p a r i n t)+(a j * A U a m b)+$ $(a k * A A b N *$ Fbent $)+(a l * A A b s * F v e n t)+(a m * A A b L * F v e n t)+(a n * A b S))$

Tabela 1 - Constantes da equação para ZB 5 e 8

\begin{tabular}{|c|c|c|c|c|c|c|c|}
\hline $\mathrm{a}$ & 4957,7051 & $\mathrm{k}$ & 267,5110 & $\mathrm{u}$ & $-1089,0840$ & ae & $-398,7255$ \\
\hline$b$ & $-4358,3120$ & 1 & $-1923,1450$ & v & 4861,2191 & af & 66,4689 \\
\hline $\mathrm{C}$ & 3875,5023 & $\mathrm{~m}$ & $-135,5828$ & w & $-703,1389$ & $\mathrm{ag}$ & $-40,6794$ \\
\hline $\mathrm{d}$ & 4833,6329 & $\mathrm{n}$ & 76,0281 & $x$ & $-3,4004$ & ah & $-78,9077$ \\
\hline $\mathrm{e}$ & 2649,1399 & 0 & $-21,8897$ & $y$ & 55,4737 & ai & 59,9755 \\
\hline$f$ & 2224,2664 & $p$ & $-1503,2234$ & $z$ & $-0,3847$ & aj & 152,9155 \\
\hline $\mathrm{g}$ & $-19,6341$ & $q$ & $-31,3561$ & aa & 338,3054 & ak & 98,2787 \\
\hline $\mathrm{h}$ & 40,0109 & $r$ & 106,7381 & $a b$ & $-556,2222$ & al & 112,5051 \\
\hline $\mathrm{i}$ & 3128,2421 & $\mathrm{~s}$ & 1524,3703 & ac & 91,9860 & $\mathrm{am}$ & 93,0504 \\
\hline $\mathrm{j}$ & $-15,3035$ & $t$ & 41,4009 & $\mathrm{ad}$ & 340,0819 & an & $-586,4518$ \\
\hline
\end{tabular}

Fonte: ELETROBRAS, PROCEL e CB3E (2012) 
Os valores de equivalentes numéricos (EqNum) de resfriamento, aquecimento, refrigeração, envoltória, ambientes e da UH são então calculados. Com o EqNum, são processadas e calculadas a eficiência energética dos ambientes, da envoltória e da UH (resfriamento, aquecimento e refrigeração), e pontuação total (PTUH).

A PT $\mathrm{TH}_{\mathrm{UH}}$ é calculada na equação a partir dos valores do EqNumEnv, resultado dos valores do EqNumEnvResfr, EqNumEnvA e EqNumEnvRefrig, calculados para cada ambiente de permanência prolongada e ponderados pela área útil. Na equação (1) entram os valores do coeficiente a (relacionado à região geográfica), do EqNumAA (Sistema de Aquecimento de Água) e Bonificações (iniciativas que aumentem a eficiência da UH):

$$
P T u h=(\text { a } x q N u m E n v)+[(1-a) x \text { EqNumAA }]+\text { Bonificações }
$$

A eficiência da Unidade Habitacional é encontrada pelo valor do PT $\mathrm{UH}_{\mathrm{UH}}$ Tabela 2.

\begin{tabular}{cc}
$\begin{array}{c}\text { Tabela 2 }- \text { Classificação do nível de eficiência de acordo com a pontuação obtida } \\
\text { Pontuação Total (PT) }\end{array}$ & Nível Eficiência \\
\hline PT $\geq 4,5$ & A \\
\hline $3,5 \leq$ PT $<4,5$ & B \\
\hline $2,5 \leq \mathrm{PT}<3,5$ & $\mathrm{C}$ \\
\hline $1,5 \leq \mathrm{PT}<2,5$ & $\mathrm{D}$ \\
\hline $\mathrm{PT}<1,5$ & $\mathrm{E}$ \\
\hline
\end{tabular}

Fonte: ELETROBRAS, PROCEL e CB3E (2012)

Os resultados calculados podem ser apresentados em diferentes formatos, como tabelas, gráficos ou figuras, de acordo com as preferências dos projetistas. Alguns exemplos de formatos de dados de saída são dados na Figura 6.

Figura 6 - Exemplos de componentes gráficos para exposição dos resultados de eficiência energética
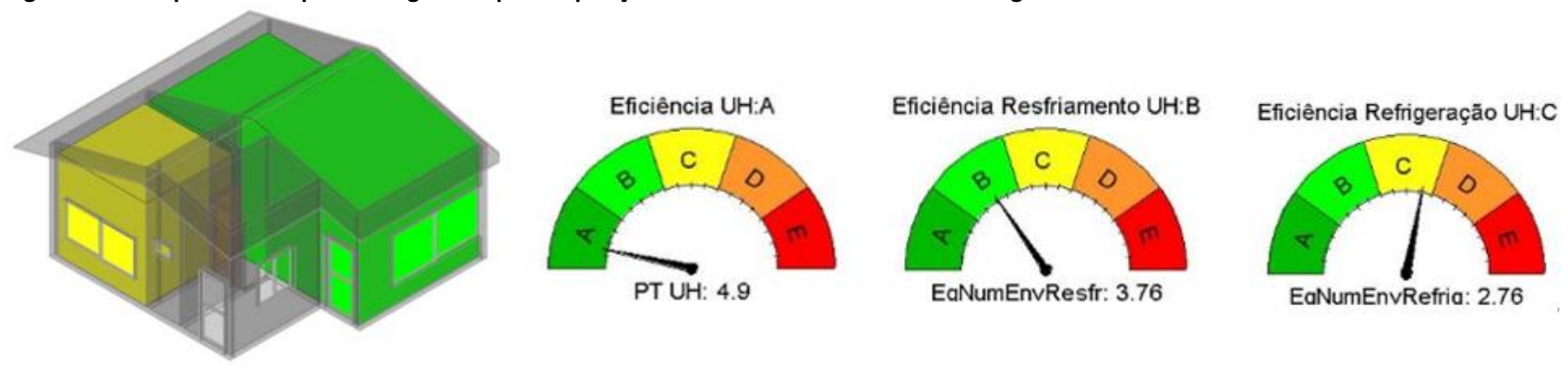

Fonte: Autores

\section{Uso da ferramenta}

O modelo escolhido para demonstração foi de uma residência unifamiliar com uma planta-baixa típica de habitação de interesse social, com pequena área construída, conforme apresentado na Figura 7. O projeto é composto por três ambientes de permanência prolongada (AmbPP): Sala, Quarto 01 e Quarto 02; dois ambientes de uso transitório: Cozinha e Banheiro; e ambiente de circulação. 


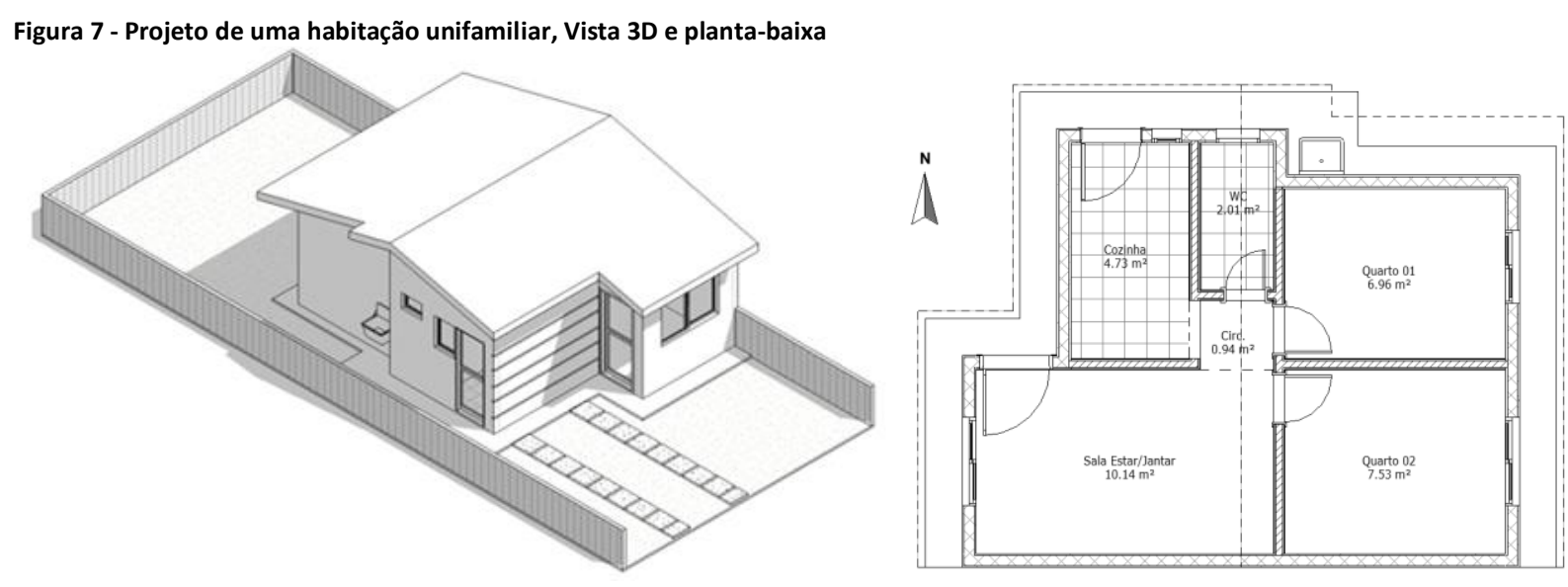

Os materiais escolhidos inicialmente para modelo base seguem uma especificação típica dessa tipologia de edificação. Como a definição do sistema construtivo é significativa para a melhoria da eficiência energética da edificação, durante os ensaios foram realizadas mudanças na composição do envelope para avaliação dos resultados.

Ao iniciar um novo projeto, desenvolve-se um processo normal de modelagem, com a diferença de que no fluxo de trabalho da IDEEA deve-se usar o template preparado para receber os parâmetros e variáveis, que serão informados e calculados durante o processo. Os scripts devem ser executados dentro do próprio programa de modelagem (Revit) usando o aplicativo Dynamo Player, um processo simples que não demanda conhecimento em programação. Para a simulação da eficiência energética do projeto, o modelo deve conter os elementos de composição arquitetônica definindo sua geometria, por meio da composição com paredes, cobertura, esquadrias (portas e janelas) e os ambientes. Algumas informações gerais do projeto são necessárias e devem ser acessadas na aba gerenciar (Manage) do Revit, onde estão disponíveis para entrada de dados na parte superior da janela, que aparece na sequência, e devem ser marcados os campos referentes a:

- EqNumAA - É o equivalente numérico do aquecimento de água, (entre nota 5, mais eficiente, e 0 , menos eficiente);

- Se possui Medidor Individual de Aquecimento de Água, Medidor Individual de Água e Medidor Individual de Energia;

- Que região geográfica pertence o projeto, Nordeste (NE), Norte (N), Centro-Oeste (CO), Sul (S), ou Sudeste (SE);

- Qual a Zona Bioclimática (ZB) do projeto: valores inteiros de 1 a 8, com base na NBR 15220-3 (ABNT, 2005).

Os elementos arquitetônicos devem ser modelados em um processo de desenvolvimento de projeto no Revit 2019, conforme metodologia de cada projetista, apenas com atenção para que os componentes - paredes, pisos, coberturas, ambientes, portas e janelas - estejam com os campos referentes à avaliação da eficiência energética preenchidos. Como exemplo, nos casos das paredes, devem ser informados os parâmetros térmicos e sua posição, se exterior ou interior.

Ao inserir os ambientes, deve-se providenciar que os mesmos contenham informações necessárias para o cálculo, como a existência de condicionador de ar Etiqueta A PROCEL, contato com pilotis (PIL), contato com o Solo (solo), dispositivo especial de ventilação na esquadria (peitoril ventilado, bandeira com abertura e outros), fechamento superior 
(cob), iluminação artificial eficiente, refrigerador eficiente, tipo de ambiente e se há ventilador de teto com etiqueta PROCEL.

A operação é realizada com o arquivo de modelagem aberto no programa Revit, não sendo necessário exportar para outro ambiente, o que permite a visualização de resultados mais rapidamente, após o processamento. Se tudo ocorrer bem no processamento dos dados, o script que faz o cálculo das equações é executado na sequência, conforme mostra a Figura 8.

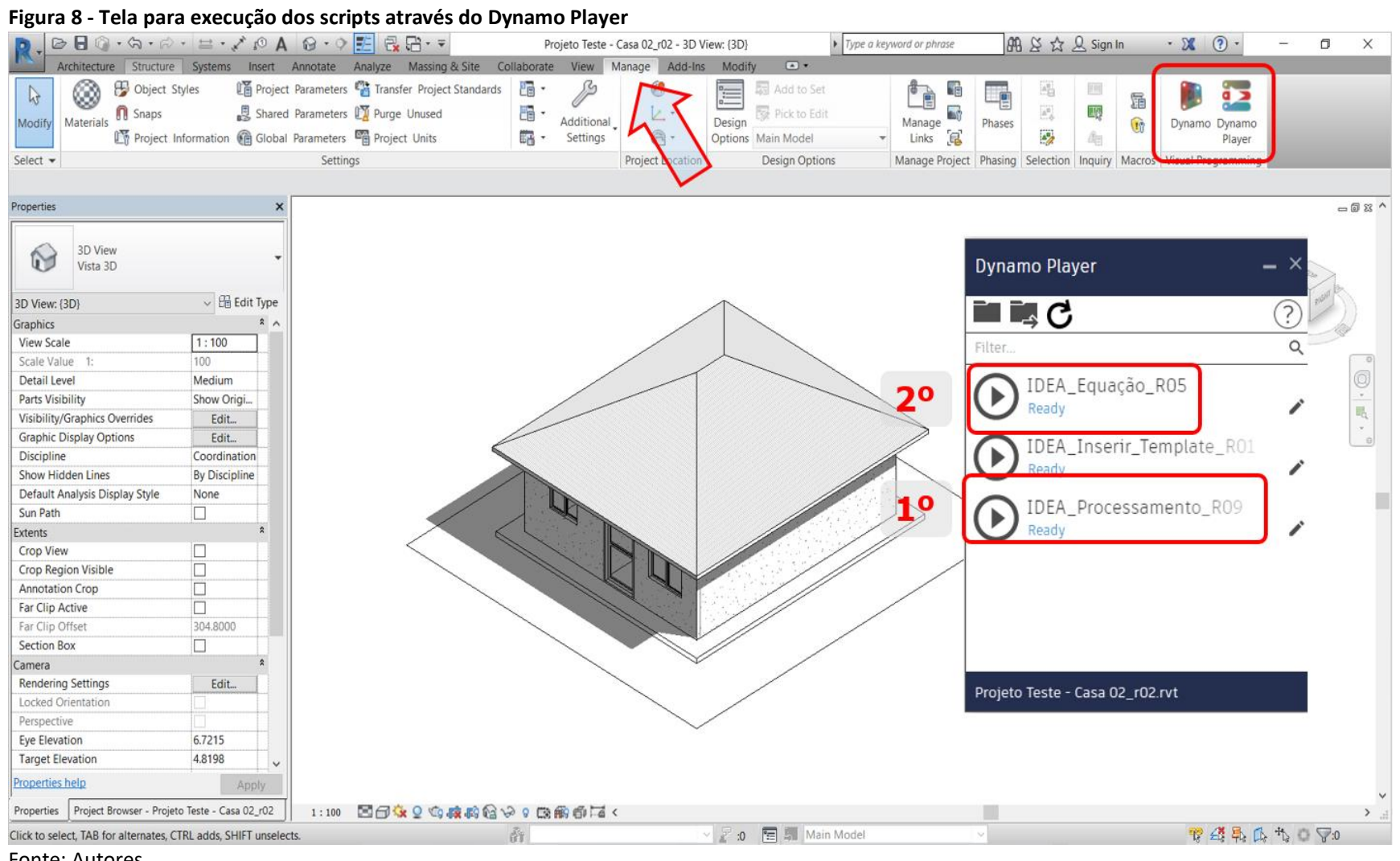

Fonte: Autores

Durante o processamento de dados, uma conferência automatizada é realizada para verificar se os dados informados estão corretos e preenchidos. Caso sejam encontradas informações inconsistentes, a ferramenta retorna com mensagens de alerta.

Para a execução dos scripts 'IDEEA_Processamento' e 'IDEEA_Equações' deste exemplo, o computador usado na pesquisa levou 20 e 15 segundos, respectivamente, o que foi considerado rápido e adequado para contribuição durante o processo projetual, levando-se em conta que o processo deverá ser repetido várias vezes durante o desenvolvimento do projeto, até se chegar ao resultado desejado.

Após a execução da ferramenta, o projetista poderá analisar os resultados encontrados em tabelas, componentes (relógios ou painéis de controle) e vistas pré-configuradas, para determinar quais as decisões a serem tomadas no projeto. O projetista também poderá criar sua própria vista, corte, planta e 3D, que melhor possa auxiliar no desenvolvimento do seu projeto.

A Figura 9 apresenta os parâmetros calculados pela ferramenta por ambiente da UH, como AS, CT e TT das paredes e cobertura, as áreas de aberturas (AA) e área de parede (APar) de cada fachada. Esses dados são utilizados para o cálculo do equivalente numérico dos ambientes de permanência prolongada. Apresenta-se também os ambientes de permanência prolongada que atendem aos pré-requisitos da envoltória 
como à transmitância térmica, à capacidade térmica e à absortância solar de componentes opacos, percentual de áreas mínimas de abertura para ventilação, iluminação natural e ventilação cruzada. Lista-se as informações dos ambientes, como área, volume, pé-direito, ventilação e iluminação natural nos banheiros, e se estes possuem ventilação e iluminação direta. Também são disponibilizados na tabela de informações do projeto, para orientação dos projetistas, o percentual de AC (Arcondicionado) eficientes na UH, porosidade das fachadas ( $N, S, L$ e O), região geográfica e zona bioclimática (ZB).

Figura 9 - Modelo de tabelas de apresentação dos resultados encontrados

\begin{tabular}{|c|c|c|c|c|c|c|c|c|c|c|c|c|c|c|c|c|c|c|c|c|}
\hline \multicolumn{21}{|c|}{ Tabela de ambiente - parâmetros } \\
\hline Nome & Tipo & $\begin{array}{l}\text { AS } \\
\text { Par. }\end{array}$ & $\begin{array}{l}\text { CT } \\
\text { Par. }\end{array}$ & $\begin{array}{l}T_{\text {Tar. }} \\
\text { Par. }\end{array}$ & $\begin{array}{l}\text { AS } \\
\text { Cob. }\end{array}$ & $\begin{array}{l}\text { CT } \\
\text { Cob. }\end{array}$ & $\begin{array}{l}T_{\text {Cob. }} \\
\text { Con }\end{array}$ & $\begin{array}{l}\text { CT } \\
\text { Alta }\end{array}$ & \begin{tabular}{|l|} 
CT \\
Baixa
\end{tabular} & $\begin{array}{l}\text { Co } \\
\text { b. }\end{array}$ & \begin{tabular}{|l}
$\mathrm{Pi}$ \\
$\mathrm{I}$.
\end{tabular} & $\begin{array}{l}\mathrm{Pi} \\
\text { so }\end{array}$ & AAL & AAN & $\mathrm{AAO}$ & AAS & APar L & A.Par N & APar O & APar S \\
\hline WC & $\mathrm{B}$ & & & & & & & & & & & & $0.00 \mathrm{~m}^{2}$ & $0.00 \mathrm{~m}^{2}$ & $0.24 \mathrm{~m}^{2}$ & $0.00 \mathrm{~m}^{2}$ & $0.00 \mathrm{~m}^{2}$ & $1.48 \mathrm{~m}^{2}$ & $3.80 \mathrm{~m}^{2}$ & $0.00 \mathrm{~m}^{2}$ \\
\hline Cozinha & C & & & & & & & & & & & & $0.00 \mathrm{~m}^{2}$ & $0.00 \mathrm{~m}^{2}$ & $1.68 \mathrm{~m}^{2}$ & $1.44 \mathrm{~m}^{2}$ & $0.00 \mathrm{~m}^{2}$ & $0.00 \mathrm{~m}^{2}$ & $5.97 \mathrm{~m}^{2}$ & $9.23 \mathrm{~m}^{2}$ \\
\hline Hall & Circ & & & & & & & & & & & & & & & & $0.00 \mathrm{~m}^{2}$ & $0.00 \mathrm{~m}^{2}$ & $0.00 \mathrm{~m}^{2}$ & $0.00 \mathrm{~m}^{2}$ \\
\hline \begin{tabular}{|l|l|} 
Quarto 01 \\
\end{tabular} & $\mathrm{D}$ & 0.14 & 425.42 & 0.81 & 0.1 & 400 & 0.1 & 1 & 0 & 1 & 0 & 1 & $0.00 \mathrm{~m}^{2}$ & $2.88 \mathrm{~m}^{2}$ & $2.88 \mathrm{~m}^{2}$ & $0.00 \mathrm{~m}^{2}$ & $0.00 \mathrm{~m}^{2}$ & $6.93 \mathrm{~m}^{2}$ & $6.03 \mathrm{~m}^{2}$ & $0.00 \mathrm{~m}^{2}$ \\
\hline \begin{tabular}{|l|} 
Quarto 02 \\
\end{tabular} & $D$ & 0.1 & 300 & 1 & 0.1 & 400 & 0.1 & 1 & 0 & 1 & 0 & 1 & $2.88 \mathrm{~m}^{2}$ & $4.50 \mathrm{~m}^{2}$ & $0.00 \mathrm{~m}^{2}$ & $0.00 \mathrm{~m}^{2}$ & $6.03 \mathrm{~m}^{2}$ & $7.50 \mathrm{~m}^{2}$ & $0.00 \mathrm{~m}^{2}$ & $0.00 \mathrm{~m}^{2}$ \\
\hline \begin{tabular}{|l|} 
Sala \\
Estar/Jantar
\end{tabular} & $\mathrm{P}$ & 0.1 & 453.24 & 0.54 & 0.1 & 700 & 0.5 & 1 & 0 & 1 & 0 & 1 & $4.50 \mathrm{~m}^{2}$ & $0.00 \mathrm{~m}^{2}$ & $1.89 \mathrm{~m}^{2}$ & $4.50 \mathrm{~m}^{2}$ & $10.84 \mathrm{~m}^{2}$ & $0.00 \mathrm{~m}^{2}$ & $2.47 \mathrm{~m}^{2}$ & $8.85 \mathrm{~m}^{2}$ \\
\hline
\end{tabular}

Tabela de ambiente - Pré-requisitos

\begin{tabular}{|c|c|c|c|c|c|c|c|c|c|c|}
\hline Nome & Tipo & Nivel & Área & Volume & Pé-direito & Pré-req.Vent. & Pré-req. Ilum. & Pré-req.Cob. & Pré-req.Par. & Vent.Alum .Dir \\
\hline WC & $\mathrm{B}$ & Térreo & $1.91 \mathrm{~m}^{2}$ & $7.96 \mathrm{~m}^{3}$ & 4.165 & - & - & - & - & Sim \\
\hline Cozinha & $\mathrm{C}$ & Térreo & $4.57 \mathrm{~m}^{2}$ & $17.65 \mathrm{~m}^{3}$ & 3.865 & - & - & - & - & Sim \\
\hline Hall & Circ & Térreo & $0.91 \mathrm{~m}^{2}$ & $3.80 \mathrm{~m}^{3}$ & & & & & & \\
\hline Quarto 01 & $\mathrm{D}$ & Térreo & $8.64 \mathrm{~m}^{2}$ & $25.93 \mathrm{~m}^{3}$ & 3 & Atende & Atende & Atende & Atende & Sim \\
\hline Quarto 02 & $\mathrm{D}$ & Térreo & $11.88 \mathrm{~m}^{2}$ & $35.64 \mathrm{~m}^{3}$ & 3 & Atende & Atende & Atende & Atende & Sim \\
\hline Sala Estar/Jantar & $\mathrm{P}$ & Térreo & $16.04 \mathrm{~m}^{2}$ & $61.38 \mathrm{~m}^{3}$ & 3.785 & Atende & Atende & Atende & Atende & Sim \\
\hline
\end{tabular}

\begin{tabular}{|c|c|c|c|c|c|c|c|c|}
\hline \multicolumn{9}{|c|}{ Informaçốes de Projeto } \\
\hline $\begin{array}{c}\text { Percentual AC } \\
\text { Eficiente }\end{array}$ & Porosidade Leste & Porosidade Norte & Porosidade Oeste & Porosidade Sul & $\begin{array}{l}\text { Pré-requisito } \\
\text { de Ventilaçẫo } \\
\text { Cruzada }\end{array}$ & $\begin{array}{c}\text { Pré-requisito de } \\
\text { Ventilaçẫo e lluminaçẫo } \\
\text { natural WC }\end{array}$ & $\begin{array}{l}\text { Regiẫo } \\
\text { Geog. }\end{array}$ & ZB \\
\hline 1 & 0.30433 & 0.316874 & 0.268029 & 0.247294 & Atende & Atende & NE & 8 \\
\hline
\end{tabular}

\begin{tabular}{|c|c|c|c|c|c|c|c|c|c|c|}
\hline \multicolumn{11}{|c|}{ Informaçốes de Projeto - Eficiência } \\
\hline Eficiência Env & EqNum Env & $\begin{array}{c}\text { Eficiência } \\
\text { Enva }\end{array}$ & EqNum Enva & $\begin{array}{l}\text { Eficiência } \\
\text { EnvRefrig }\end{array}$ & $\begin{array}{l}\text { EqNum } \\
\text { EnvRefrig }\end{array}$ & $\begin{array}{l}\text { Eficiência } \\
\text { EnvRestr }\end{array}$ & $\begin{array}{l}\text { EqNum } \\
\text { EnvRestr }\end{array}$ & EqNum AA & PTuh & Eficiência UH \\
\hline $\mathrm{B}$ & 3.76362 & & & $\mathrm{C}$ & 2.76362 & $\mathrm{~B}$ & 3.76362 & 5 & 4.9 & A \\
\hline
\end{tabular}

\begin{tabular}{|c|c|c|c|c|c|c|c|c|c|c|c|}
\hline \multicolumn{12}{|c|}{ Informaçốes de Projeto - Bonificaçốes } \\
\hline $\begin{array}{c}\text { Centro } \\
\text { Geométrico } \mathrm{Ab}\end{array}$ & $\begin{array}{l}\text { Condiciona } \\
\text { mento de Ar }\end{array}$ & $\begin{array}{c}\text { Dispositivos } \\
\text { Especiais }\end{array}$ & $\begin{array}{l}\text { Iluminaçẫo } \\
\text { Artificial }\end{array}$ & $\begin{array}{c}\text { Medidor } \\
\text { Individual A.A }\end{array}$ & $\begin{array}{l}\text { Permeabi } \\
\text { lidade Ar }\end{array}$ & Porosidade & $\begin{array}{l}\text { Profundidade } \\
\text { de Iluminaçẫo }\end{array}$ & $\begin{array}{l}\text { Reflet ância } \\
\text { Teto }\end{array}$ & $\begin{array}{l}\text { Refriger } \\
\text { adores }\end{array}$ & \begin{tabular}{|c|} 
Uso \\
Racional \\
de Água
\end{tabular} & $\begin{array}{l}\text { Ventilado } \\
r \text { de Teto }\end{array}$ \\
\hline 0 & 0 & 0.16 & 0.05 & 0.1 & 0 & 0.12 & 0.2 & 0 & 0.1 & 0.2 & 0.1 \\
\hline
\end{tabular}

Fonte: Autores.

Algumas soluções projetuais que potencializam a eficiência da UH poderão ganhar até um ponto na classificação geral da UH somando os pontos obtidos por meio das bonificações. Para tanto devem ser justificadas e comprovadas. Essas soluções estão relacionadas a ventilação natural, iluminação natural, uso racional de água, condicionamento artificial de ar, iluminação artificial, ventiladores de teto e refrigeradores instalados na UH e medição individualizada do sistema de aquecimento de água. As bonificações alcançadas no projeto são apresentadas em tabelas, e componentes de anotação, podendo ser dispostas em plantas para análises e apresentação.

Na Figura 10 apresenta uma prancha padrão disponibilizada em forma de template, com os elementos principais para análise da eficiência energética da UH. Além das tabelas descritas anteriormente, o projetista pode analisar plantas e vistas 3D onde 
graficamente se demonstra a eficiência energética através dos valores de GHR, CR e CA de cada ambiente de permanência prolongada, onde estes vêm com a cor específica calculada. Componentes do tipo Relógios de Eficiência são usados para ilustrar melhor os resultados obtidos da $\mathrm{UH}$, e variam de $\mathrm{A}$ a $\mathrm{E}$, de acordo com a eficiência de resfriamento, refrigeração e aquecimento encontrada.

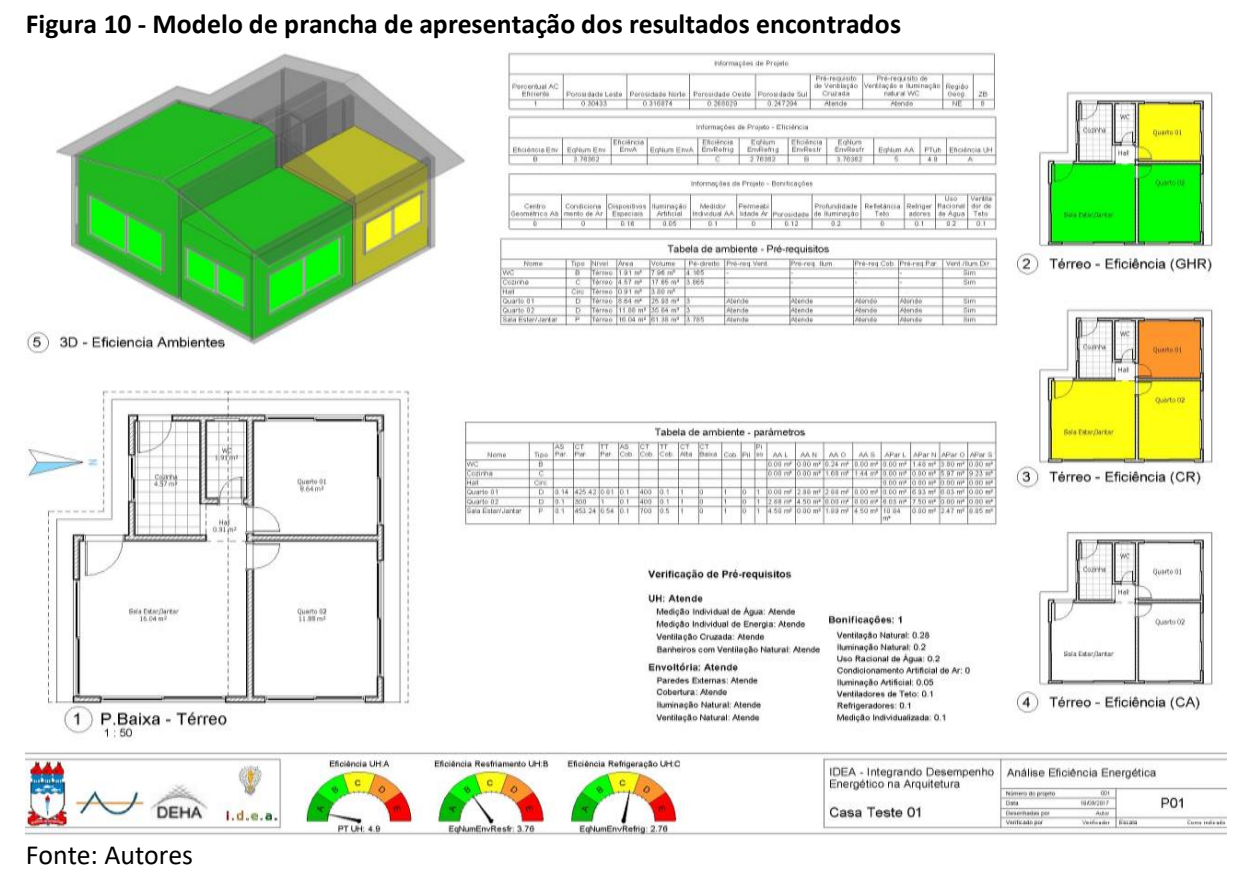

\section{Simulações e avaliação dos resultados}

No processo tradicional de cálculo de eficiência energética do RTQ-R pode ser utilizada a planilha de cálculo disponibilizada pela Eletrobrás, formato Excel, onde as informações são alimentadas manualmente com base nos desenhos técnicos do projeto. A planilha está disponibilizada no site do PROCEL Edifica³ ${ }^{3}$.

Para a verificação dos resultados encontrados pela ferramenta IDEEA, as variáveis de entrada foram inseridas manualmente na planilha os resultados das variáveis de saída foram conferidos. Os resultados apresentados foram os mesmos dos calculados pela planilha da Eletrobrás, demonstrando que a ferramenta automatiza a extração das variáveis e cálculos apresentando os resultados igualmente ao processo manual.

Entretanto, um valor encontrado distingue-se daqueles obtidos através dos cálculos gerados pela planilha, em decorrência do pré-requisito relacionado à ventilação natural, que determina que, caso os valores mínimos não sejam atendidos, seja determinado o nível máximo "C" de eficiência para a UH. Isto corresponde a uma regra do RTQ-R que estabelece que as UHs devem atender aos pré-requisitos de ventilação natural, tendo aberturas para ventilação com áreas mínimas correspondentes a determinado percentual em relação à área dos ambientes de permanência prolongada. O não atendimento ao pré-requisito implica na obtenção de, no máximo, 3 para o EqNum no equivalente numérico da envoltória do ambiente para resfriamento (EqNumEnvAmbResfr). Tal situação corresponde ao nível $C$ de eficiência energética neste quesito. Tal regra consta na ferramenta IDEEA, mas não foi inserida na planilha Eletrobrás, provavelmente por conta de limitações desta. Para esclarecer a diferença, a forma de processamento de dados na ferramenta foi alterada, alinhando ao cálculo da planilha Eletrobrás, gerando resultados idênticos à planilha. No entanto, manteve-se na 
OLIVEIRA, Fernando; BITTENCOURT, Leonardo; DÓRIA, David

Uma Ferramenta BIM de Simulação de Eficiência Energética nas Fases Iniciais de Projeto

ferramenta o processamento original, por ser realizado conforme disposto no RTQ-R (ELETROBRAS; PROCEL; CB3E, 2012).

Alterações foram propostas para o modelo base, conforme demonstrado na Tabela 3.

\begin{tabular}{cc} 
Tabela 3 - Ensaios realizados no projeto-piloto & \\
\hline Tipo & Número de ensaios \\
\hline Orientação Norte & 08 \\
\hline Materiais envoltória & 08 \\
\hline Esquadrias & 04 \\
\hline Geometria & 04 \\
\hline Total: & 24 \\
\hline
\end{tabular}

Fonte: Autores

As oitos principais orientações solares em relação ao norte do projeto foram variadas em $45^{\circ}$ para cada ensaio, em um total de oito ensaios, como mostra a Figura 10.

Em seguida, os materiais das vedações externas (paredes) e coberturas foram alterados, em uma combinação de vários tipos de materiais com características térmicas distintas.

Num terceiro momento, foram alteradas as esquadrias dos ambientes de permanência prolongada (Sala e Quartos 1 e 2), mudando a área de iluminação e ventilação de cada ambiente e, consequentemente, variando o percentual de área envidraçada na fachada (Tabela 3).

Figura 10 - Planta-baixa projeto piloto: orientações de $0^{\circ}$ a $315^{\circ}$

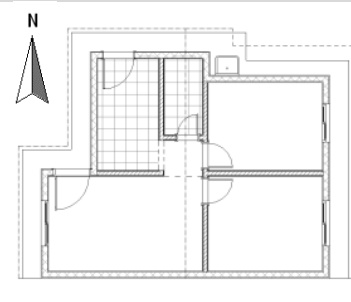

$0^{\circ}$

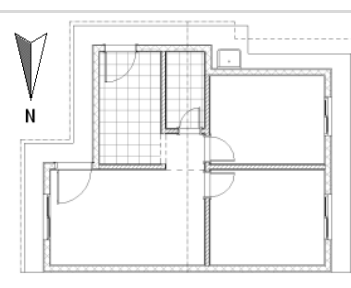

$180^{\circ}$

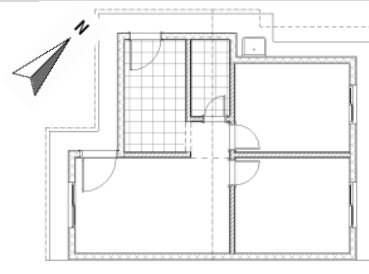

$45^{\circ}$

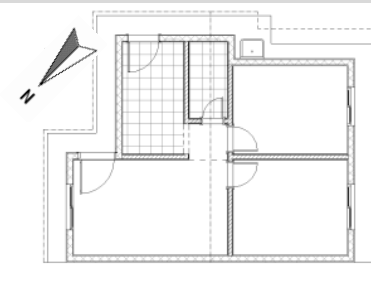

$225^{\circ}$

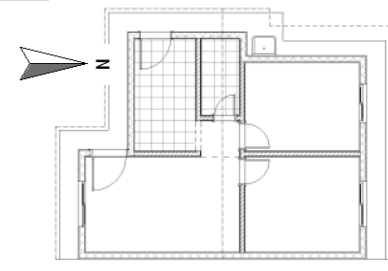

$90^{\circ}$

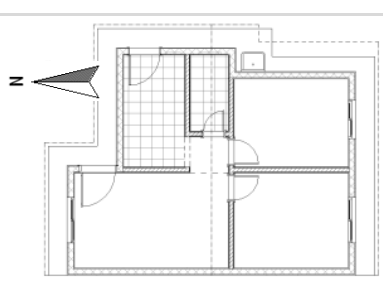

$270^{\circ}$

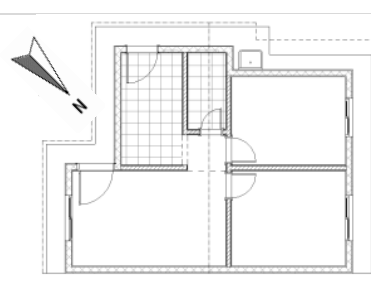

$135^{\circ}$

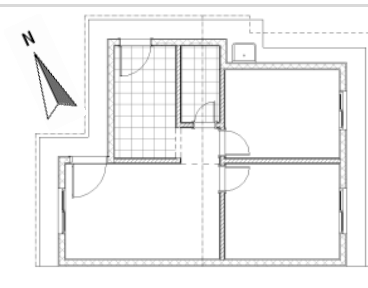

$315^{\circ}$

Fonte: Autores

Tabela 4 - Ensaios com variações (04) nas esquadrias (janelas) do projeto piloto - base

\begin{tabular}{|c|c|}
\hline \multirow{2}{*}{ MODELO } & ESQUADRIAS (APP) \\
\hline & Especificações \\
\hline MOD. BASE & Sala: $1,20 \times 1,20 \mathrm{~m}$; Quarto 1: 1,00 x 1,20m; Quarto 2: $1,20 \times 1,20 \mathrm{~m}$; \\
\hline MOD. ESQ-01 & Sala: $1,40 \times 1,20 \mathrm{~m}$; Quarto 1: 1,20 x 1,20m; Quarto 2: $1,40 \times 1,20 \mathrm{~m}$; \\
\hline MOD. ESQ-02 & Sala: $1,60 \times 1,20 \mathrm{~m}$; Quarto 1: 1,40 x 1,20m; Quarto 2: $1,60 \times 1,20 \mathrm{~m}$; \\
\hline MOD. ESQ-03 & Sala: $1,80 \times 1,20 \mathrm{~m}$; Quarto 1: 1,60 x 1,20m; Quarto 2: $1,80 \times 1,20 \mathrm{~m}$; \\
\hline MOD. ESQ-04 & Sala: $2,00 \times 1,20 \mathrm{~m}$; Quarto 1: 1,80 x 1,20m; Quarto 2: 2,00 x 1,20m; \\
\hline
\end{tabular}

Fonte: Autores

Nesse último ensaio variou-se a geometria do projeto piloto - base, gerando, dessa forma, quatro arranjos, conforme ilustrado na Tabela 5 . 
OLIVEIRA, Fernando; BITTENCOURT, Leonardo; DÓRIA, David

Uma Ferramenta BIM de Simulação de Eficiência Energética nas Fases Iniciais de Projeto

Tabela 5 - Ensaios com variações (04) na geometria (APP) do projeto piloto - base

\begin{tabular}{|c|c|c|c|c|c|}
\hline \multirow{4}{*}{ MOD. BASE } & \multicolumn{5}{|c|}{ GEOMETRIA (APP) } \\
\cline { 2 - 6 } & Especificações & Larg. & Comp. & Área & Pé-Direito médio \\
\cline { 2 - 6 } & SALA & 2,51 & 4,05 & 10,14 & 3,26 \\
\cline { 2 - 6 } & QUARTO 1 & 2,32 & 3,01 & 6,96 & 3,18 \\
\hline \multirow{3}{*}{ MOD. GEO-01 } & QUARTO 2 & 2,51 & 3,01 & 7,56 & 3,18 \\
\cline { 2 - 6 } & SALA & 2,51 & 4,55 & 11,41 & 3,29 \\
\cline { 2 - 6 } & QUARTO 1 & 2,32 & 3,01 & 6,96 & 3,18 \\
\hline \multirow{3}{*}{ MOD. GEO-02 } & QUARTO 2 & 2,51 & 3,01 & 7,56 & 3,18 \\
\cline { 2 - 6 } & SALA & 3,01 & 4,55 & 13,70 & 3,29 \\
\cline { 2 - 6 } & QUARTO 1 & 2,32 & 3,01 & 6,96 & 3,18 \\
\hline \multirow{3}{*}{ MOD. GEO-03 } & QUARTO 2 & 3,01 & 3,01 & 9,05 & 3,18 \\
\cline { 2 - 6 } & SALA & 3,01 & 4,55 & 13,70 & 3,32 \\
\cline { 2 - 6 } & QUARTO 1 & 2,32 & 3,51 & 8,13 & 3,25 \\
\hline \multirow{3}{*}{ MOD. GEO-04 } & QUARTO 2 & 3,01 & 3,51 & 10,57 & 3,25 \\
\cline { 2 - 6 } & SALA & 3,01 & 4,55 & 13,70 & 3,32 \\
\cline { 2 - 6 } & QUARTO 1 & 2,95 & 3,51 & 10,34 & 3,25 \\
\cline { 2 - 6 } & QUARTO 2 & 3,01 & 3,51 & 10,57 & 3,25 \\
\hline
\end{tabular}

Fonte: Autores

Para cada ensaio realizado, foram processados todos os cálculos para a extração dos valores de todos os parâmetros que determinam a eficiência energética do modelo simulado, comparando com os resultados processados manualmente pela planilha Excel. Todos os valores encontrados foram tabelados e conferidos com a referência utilizada, coincidindo integralmente os resultados e confirmando a consistência nos cálculos da ferramenta.

Durante a realização do estudo de caso, foram realizados testes para validação em todas as zonas bioclimáticas, as quais mantiveram a mesma precisão dos resultados da planilha.

\section{Workshop}

Nas atividades didáticas do workshop para aplicação da ferramenta, buscou-se seguir um roteiro com etapas passo-a-passo para facilitar a compreensão do processo, salientando-se que a sequência apresentada seria apenas uma sugestão e que cada participante poderia adotar sua metodologia própria.

Os participantes apresentaram heterogeneidade de conhecimento nos temas abordados e nos níveis de formação (participaram três professores, seis arquitetos e oito alunos de graduação), sendo garantido para eles o anonimato nas publicações que viessem a ocorrer no futuro.

Os participantes receberam, inicialmente, um nivelamento de conhecimento abordando os assuntos eficiência energética, etiquetagem e PROCEL Edifica, com duração de quatro horas, sendo abordados conceitos importantes para a utilização da ferramenta. Em seguida, ensinou-se como utilizar a ferramenta IDEA e os procedimentos a serem adotados na modelagem virtual.

Todos os participantes desenvolveram a modelagem de uma habitação unifamiliar e apresentaram resultados positivos quanto à aprendizagem, à aplicação e à possibilidade de utilização futura no seu processo de projeto. Os participantes tiveram pouca dificuldade em usar a ferramenta e em pouco tempo (40 minutos) já estavam extraindo resultados sobre a eficiência do projeto desenvolvido e fazendo ajustes para a melhoria do desempenho energético. Apesar do tempo curto, a operação da ferramenta foi assimilada facilmente. 
Os resultados apresentados (modelagens do projeto, acompanhamento da aplicação da ferramenta, respostas ao questionário aplicado de avaliação da ferramenta) demonstram que os participantes tiveram uma boa assimilação no auxílio ao processo de projeto. Os participantes avaliam como excelente (10), ótima (9), boa (8) e suficiente (7) a questão sobre o uso da ferramenta para o desenvolvimento de projeto e simulação de desempenho energético, e as atividades desenvolvidas com a IDEEA integrando o processo de projeto e desempenho energético (Figura 11).

Figura 11 - Avaliação da ferramenta IDEEA pelos participantes

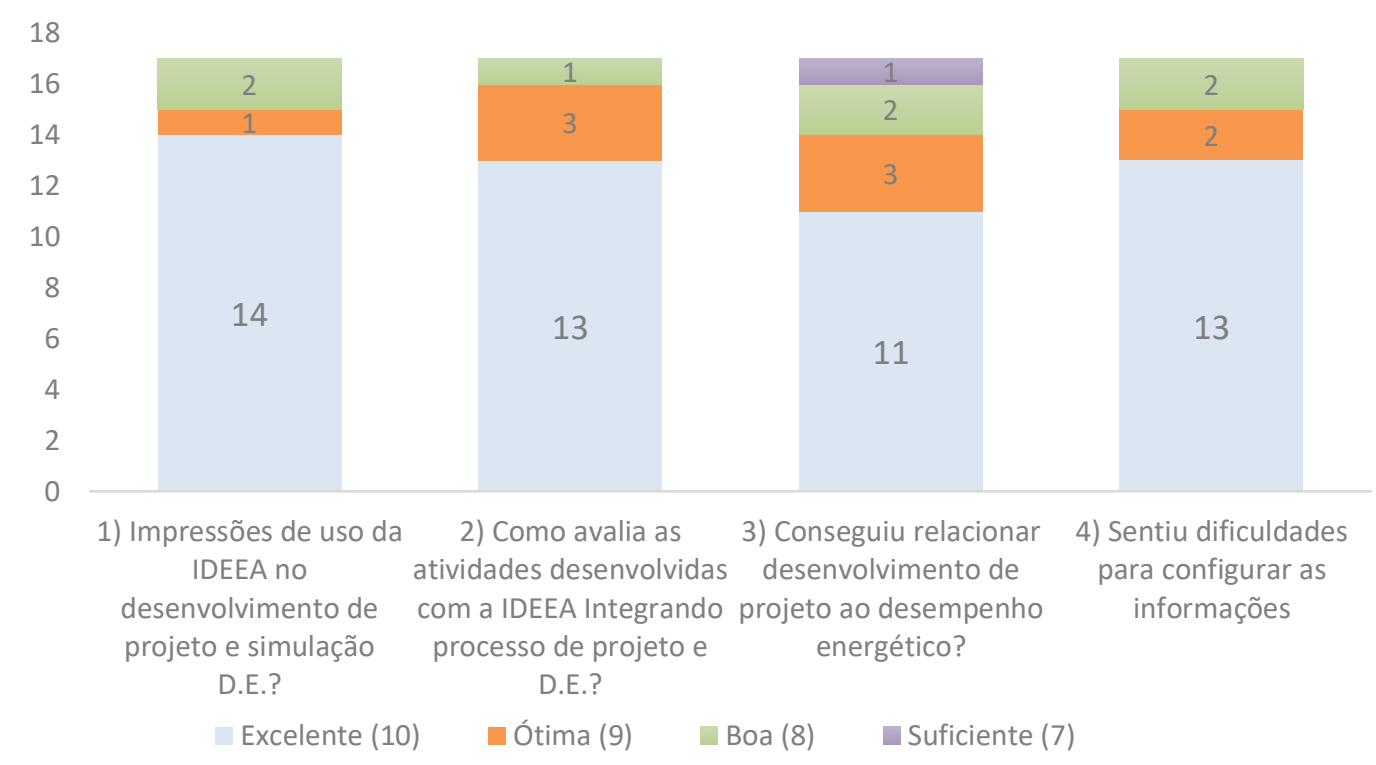

Fonte: Autores

A maior parte dos participantes também avalia que conseguiu relacionar bem quanto ao desenvolvimento de projeto ao desempenho energético, demonstrando que não sentiram dificuldades na utilização da ferramenta e revelando que aplicariam a IDEEA em seus projetos. Apesar da boa avaliação, essa questão teve avaliação inferior às outras questões, e deve ser um ponto de melhoramento para outras oficinas. Dentre as sugestões ou críticas dos participantes sobre a ferramenta foi a de transformar em um plug-in inserido no Revit, e disponibilizar aos arquitetos e projetistas.

\section{Conclusão}

Esse artigo teve como objetivo apresentar o desenvolvimento de uma ferramenta computacional denominada IDEEA, capaz de realizar simulações de eficiência energética de edificações ainda em fase de elaboração do projeto arquitetônico.

Com o auxílio da ferramenta, simulações podem ser feitas para se obter o nível de eficiência energética do projeto de habitações unifamiliares de acordo com os critérios de desempenho adotados do Regulamento Técnico da Qualidade para o Nível de Eficiência Energética de Edificações Residenciais (RTQ-R). Este regulamento é padrão de referência brasileira para o tema, e estabelece as condições para a classificação do nível de eficiência energética de edificações residenciais. Possibilitando assim, a obtenção da Etiqueta Nacional de Conservação de Energia (ENCE), concedida no âmbito do Programa Brasileiro de Etiquetagem (PBE) do INMETRO (ELETROBRAS; PROCEL; CB3E, 2012). 
Ao contrário do que ocorre com outras ferramentas, que muitas vezes são usadas para examinar a eficiência energética na etapa final do projeto, a IDEEA pode ser utilizada desde as fases iniciais, momento em que a modelagem (geometria composta por paredes, esquadrias, cobertura e ambientes) está minimamente configurada, permitindo o acompanhamento do desenvolvimento do projeto à medida que este evolui. Esta característica possibilita ao projetista realizar correções na fase inicial, quando as mudanças no projeto produzem menores impactos nos custos e prazos do processo de desenvolvimento da proposta arquitetônica. A principal contribuição é permitir que sejam avaliados os impactos de eventuais medidas adotadas pelo projetista no sentido de obter uma melhor eficiência energética.

A ferramenta IDEEA apresenta respostas para as soluções de projeto durante o processo de concepção e desenvolvimento de projeto em BIM dentro de um programa computacional de modelagem (Revit 2019), auxiliando o projetista na escolha do partido arquitetônico de maior eficiência energética. São calculadas as informações da eficiência energética dos ambientes, da envoltória e da UH (resfriamento, aquecimento e refrigeração) e pontuação total. Estes desempenhos são apresentados de forma tabular, em dashboards ou mapeadas em escala de cor nos ambientes 3D. A ferramenta IDEEA pode ser integrada a um amplo espectro de cenários de projeto e sendo de fácil implantação por projetistas no processo de projeto.

Ao possibilitar a simulação e avaliação da eficiência energética da edificação, segundo o RTQ-R, a IDEEA permite a tomada de decisões e evita o desenvolvimento de um projeto inadequado do ponto de vista energético. Evita também o desperdício de tempo e de capital, como usualmente ocorre ao se avaliar o projeto apenas em fases avançadas.

Pretende-se com a presente pesquisa, incluir ferramentas de cálculo para edificações residenciais multifamiliar, além de adequar a ferramenta para o novo método de avaliação energética de edificações $\left(\mathrm{CB}_{3} \mathrm{E}^{4}\right)$. O novo método se baseia no consumo de energia primária, e compara a edificação considerando suas características reais com a mesma edificação, adotando-se características de referências, que equivalem à classe $D$ de eficiência energética. A intenção é que a ferramenta também incorpore outras tipologias de edificações, como comerciais, de serviço e institucionais (RTQ-C).

\section{Agradecimentos}

O presente trabalho foi realizado com apoio da Coordenação de Aperfeiçoamento de Pessoal de Nível Superior Brasil (CAPES) - Código de Financiamento 001 e da Fundação de Amparo à Pesquisa do Estado de Alagoas (FAPEAL), Processo No 23038.023347/2016-74, por meio de bolsa de doutorado.

\section{Notas}

(1) Template é um arquivo modelo a ser seguido, com uma estrutura predefinida que facilita o desenvolvimento e criação do conteúdo a partir de algo construído a priori.

(2) Scripts são "roteiros" seguidos por sistemas computacionais e trazem informações que são processadas e transformadas em ações efetuadas por um programa principal.

(3) ELETROBRAS. Procel Edifica, Etiquetagem, Edificações Residenciais, Planilhas e Catálogos. Disponível em http://pbeedifica.com.br/etiquetagem/publica/planilhas-catalogos/. Acesso em: 20 de ago. de 2018.

(4) CB3E é o novo método de avaliação energética de edificações com base em energia primária. Disponível em: http://cb3e.ufsc.br/etiquetagem/desenvolvimento/atividades-2012-2016/trabalho-1/pesquisas. 


\section{Referências}

ABNT - ASSOCIAÇÃO BRASILEIRA DE NORMAS TÉCNICAS. NBR 15220: Desempenho térmico de edificações Parte 1: Definições, símbolos e unidades. Associação Brasileira de Normas Técnica. Rio de Janeiro, 2005.

ANDRADE, Max Lira Veras Xavier de. Projeto performativo na prática arquitetônica recente: estrutura Conceitual. 2012. 436 p. Tese (doutorado) - Universidade Estadual de Campinas, Faculdade de Engenharia Civil, Arquitetura e Urbanismo, Campinas, SP. Disponível em: <http://www.repositorio.unicamp.br/handle/REPOSIP/258559>. Acesso em: 20 ago. 2018.

BAZJANAC, Vladimir. IFC BIM-Based Methodology for Semi-Automated Building Energy Performance Simulation. In: INTERNATIONAL CONFERENCE ON INFORMATION TECHNOLOGY IN CONSTRUCTION, 25., 2008, Santiago. Proceedings [...]. Santiago: CIB-W78, 2008.

BITTENCOURT, Leonardo Salazar; MONTEIRO, Leonardo; YANNAS, Simos. Conforto Ambiental e as possibilidades do Modelo Adaptativo. In: GONÇALVES, Joana; BODE, Klaus. Edifício Ambiental. São Paulo: Oficina de Textos, 2015. p. 27-35. ISBN 978-85-7975-130-1.

BORGSTEIN, E.H.; LAMBERTS, R.; HENSEN, J.L.M. Evaluating energy performance in non-domestic buildings: A review. Energy and Buildings, v. 128, p. 734-755, set. 2016. DOI: https://doi.org/10.1016/j.enbuild.2016.07.018

BRASIL. Decreto no 9.377, de 17 de maio de 2018. Institui a Estratégia Nacional de Disseminação do Building Information Modelling. Brasília.

BRASIL. Decreto no 9.983, de 22 de agosto de 2019. Dispõe sobre a Estratégia Nacional de Disseminação do Building Information Modelling e institui o Comitê Gestor da Estratégia do Building Information Modelling. Brasília.

CASALS, Xavier García. Analysis of building energy regulation and certification in Europe: Their role, limitations and differences. Energy and Buildings, v. 38, n. 5, p. 381-392, maio 2006.

DOI:https://doi.org/10.1016/j.enbuild.2005.05.004

CULLEN, Jonathan M.; ALLWOOD, Julian M.; BORGSTEIN, Edward H. Reducing Energy Demand: What Are the Practical Limits? Environmental Science \& Technology, v. 45, n. 4, p. 1711-1718, 15 fev. 2011.

DOI:https://doi.org/10.1021/es102641n

DAVIS, Daniel. The MacLeamy curve. 2004. Disponível em: <http://www.danieldavis.com/macleamy/>. Acesso em: 10 jan. 2017.

DEHOUCK, Rémi. The maturity of visual programming. Blog. Disponível em: http://www.craft.ai/blog/the-maturityof-visual-programming/. Acesso em: 17 abr. 2017.

DRESCH, Aline; LACERDA, Daniel Pacheco; ANTUNES JÚNIOR, José Antonio Valle. Design science research: método de pesquisa para avanço da ciência e tecnologia. Porto Alegre, Brasil: Bookman, 2015. 181 p. ISBN 978-85-8260-2997.

EASTMAN, Chuck et al. BIM Handbook: A Guide to Building Information Modeling for Owners, Managers, Designers, Engineers and Contractors. [S.I.]: John Wiley \& Sons, 2011. ISBN 978-0-470-18528-5.

ELETROBRAS; PROCEL; GB3E. Manual para Aplicação do RTQ-R, v, 4.2, Versão 1, 2012.

FOSSATI, Michele et al. Building energy efficiency: An overview of the Brazilian residential labeling scheme. Renewable and Sustainable Energy Reviews, v. 65, p. 1216-1231, nov. 2016. DOI:https://doi.org/10.1016/j.rser.2016.06.048

FREIRE, Marcia Rebouças; AMORIM, Arivaldo Leão. A abordagem BIM como contribuição para a eficiência energética no ambiente construído. In: ENCONTRO DE TECNOLOGIA DE INFORMAÇÃO E COMUNICAÇÃO NA CONSTRUÇÃO, 5., 2011, Salvador. Anais[...]. Porto Alegre: ANTAC, 2011. 
HOJJATI, Behjat; WADE, Steven H. US household energy consumption and intensity trends: a decomposition approach. Energy Policy, v. 48, p. 304-314, 2012. DOI:https://doi.org/10.1016/j.enpol.2012.05.024

INMETRO - INSTITUTO NACIONAL DE METROLOGIA, QUALIDADE E TECNOLOGIA. Anexo da Portaria n..$^{\circ} \mathbf{1 8}$, de 16 de janeiro de 2012. REGULAMENTO TÉCNICO DA QUALIDADE PARA O NÍVEL DE EFICIÊNCIA ENERGÉTICA EDIFICAÇÕES RESIDENCIAIS, v. 2.2, 2012. Disponível em:

http://www.pbeedifica.com.br/sites/default/files/projetos/etiquetagem/residencial/downloads/RTQR.pdf.

INMETRO - INSTITUTO NACIONAL DE METROLOGIA, QUALIDADE E TECNOLOGIA. Anexo Geral V da Portaria n. ${ }^{\circ} \mathbf{5 0}$, de 1 de fevereiro de 201. Catálogo de propriedades térmicas de paredes, coberturas e vidros, 2013. Disponível em: http://www.pbeedifica.com.br/sites/default/files/AnexoV_CatalogoPropriedadesTermicas\%20v27NOV2017.pdf

INTERNATIONAL ENERGY AGENCY. Capturing the Multiple Benefits of Energy Efficiency. Paris, France, 2014.

KUMAR, Sumedha. Interoperability Between Building Information Models (BIM) and Energy Analysis Programs. 2008. 149p. Thesis (Master of Building Science) - Faculty of the School of Architecture, University of Southern California, California, 2008.

LACHAUER, Lorenz; RIPPMANN, Matthias; BLOCK, Philippe. Form Finding to Fabrication: A digital design process for masonry vaults. In: ANNUAL SYMPOSIA OF THE INTERNATIONAL ASSOCIATION FOR SHELL AND SPATIAL STRUCTURES, 2010, Shanghai. Proceedings [...]. Shanghai: IASS, 2010.

LAUSTSEN, Jens. Energy efficiency requirements in building codes: energy efficiency policies for new buildings. International Energy Agency (IEA), p. 477-488, 2008.

MME - Ministério das Minas e Energia. Balanço Energético Nacional 2018 - Ano base 2017. p. 62, 2018.

MONTEIRO, Ari. Utilização de Linguagem de Programação Visual para Elaboração de Modelos BIM LOD 400. In: BIM INTERNATIONAL CONFERENCE, 4., 2016, São Paulo. Proceedings [...]. São Paulo : BIMMI, 2016. p. 1-4.

PEFFERS, Ken et al. The design science research process: a model for producing and presenting information systems research. In: INTERNATIONAL CONFERENCE ON DESIGN SCIENCE IN INFORMATION SYSTEMS AND TECHNOLOGY, 1., 2006, Claremont. Proceedings [... ]. Claremont: DESRIST, 2006. p. 83-106.

PÉREZ-LOMBARD, Luis; ORTIZ, José; POUT, Christine. A review on buildings energy consumption information. Energy and Buildings, v. 40, n. 3, p. 394-398, 2008. DOI: https://doi.org/10.1016/j.enbuild.2007.03.007

RUSCHEL, R. et al. O papel das ferramentas BIM de integração e compartilhamento no processo de projeto na indústria da construção civil. REEC - Revista Eletrônica de Engenharia Civil, v. 7, n. 3, 12 dez. 2013. DOI:https://doi.org/10.5216/reec.v7i3.27487

SANTIAGO, Pedro. BIM to BEM as Teaching Methodology to Support Sustainable Construction Decisions. Periodica Polytechnica Architecture, v. 47, n. 2, p. 94-98, 2016. DOI: https://doi.org/10.3311/PPar.10190

STAVRIC, Milena; MARINA, Ognen. Parametric modeling for advanced architecture. International journal of applied mathematics and informatics, v. 5, n. 1, p. 9-16, 2011.

SUCCAR, Bilal. Building information modelling framework: A research and delivery foundation for industry stakeholders. Automation in Construction, v. 18, n. 3, p. 357-375, maio 2009.

DOI:https://doi.org/10.1016/j.autcon.2008.10.003

THUESEN, N.; KIRKEGAARD, P.H.; JENSEN, R. Lunden. Evalution of BIM and Ecotect for conceptual architectural design analysis. In: INTERNATIONAL CONFERENCE ON COMPUTING IN CIVIL AND BUILDING ENGINEERING, 13., 2010, Nottingham. Proceedings [...]. Nottingham: Nottingham University Press, 2010. p. 169-170

TOBIN, J. AtomicBIM: Splitting Data to Unleash BIM's Power. AECbytes, Features, 2008. 
OLIVEIRA, Fernando; BITTENCOURT, Leonardo; DÓRIA, David

Uma Ferramenta BIM de Simulação de Eficiência Energética nas Fases Iniciais de Projeto

UMAKOSHI, Erika. Avaliação de Desempenho Ambiental e Arquitetura Paramétrica Generativa para o projeto do edifício Alto. 2014. 253 f. Tese (Doutorado) - Faculdade de Arquitetura e Urbanismo - Universidade de São Paulo, São Paulo, 2014.

\section{${ }^{1}$ Fernando Márcio de Oliveira}

Arquiteto. Doutor. Professor Adjunto Universidade Federal de Sergipe. Endereço postal: Rua Desembargador José Sotero, 53, 13 de julho, Aracaju, SE, Brasil, CEP 49020-110

\section{${ }^{2}$ Leonardo Salazar Bittencourt}

Arquiteto. Doutor. Professor Voluntário Universidade Federal de Alagoas. Endereço postal: Rua Cláudio Ramos, 431, apto. 601, Ponta Verde, Maceió, AL, Brasil, CEP 57035-020

\section{David Rodrigues Silva Dória}

Arquiteto. Mestrando Bartlett, UCL. Endereço postal: Rua Oscar Valois Galvão, 29, Aracaju, SE, Brasil, CEP 49027-220 